OPEN ACCESS

Edited by:

Aziz Amine,

University of Hassan II Casablanca,

Morocco

Reviewed by:

Vincenzo Vaiano,

University of Salerno, Italy

Jia Hong Pan,

North China Electric Power University,

China

${ }^{*}$ Correspondence:

Omotayo A. Arotiba oarotiba@uj.ac.za

Specialty section:

This article was submitted to Catalysis and Photocatalysis, a section of the journal

Frontiers in Chemistry

Received: 28 November 2020 Accepted: 19 February 2021

Published: 15 April 2021

Citation:

Nkwachukwu OV and Arotiba OA (2021) Perovskite Oxide-Based Materials for Photocatalytic and Photoelectrocatalytic Treatment

of Water.

Front. Chem. 9:634630 doi: 10.3389/fchem.2021.634630

\section{Perovskite Oxide-Based Materials for Photocatalytic and Photoelectrocatalytic Treatment of Water}

\author{
Oluchi V. Nkwachukwu ${ }^{1}$ and Omotayo A. Arotiba ${ }^{1,2 *}$ \\ ${ }^{1}$ Department of Chemical Sciences, University of Johannesburg, Johannesburg, South Africa, ${ }^{2}$ Centre for Nanomaterials Science \\ Research, University of Johannesburg, Johannesburg, South Africa
}

Meeting the global challenge of water availability necessitates diversification from traditional water treatment methods to other complementary methods, such as photocatalysis and photoelectrocatalysis (PEC), for a more robust solution. Materials play very important roles in the development of these newer methods. Thus, the quest and applications of a myriad of materials are ongoing areas of water research. Perovskite and perovskite-related materials, which have been largely explored in the energy sectors, are potential materials in water treatment technologies. In this review, attention is paid to the recent progress in the application of perovskite materials in photocatalytic and photoelectrocatalytic degradation of organic pollutants in water. Water treatment applications of lanthanum, ferrite, titanate, and tantalum (and others)-based perovskites are discussed. The chemical nature and different synthetic routes of perovskites or perovskite composites are presented as fundamental to applications.

Keywords: perovskites, water treatment, photocatalysis, photoelectrocatalysis, degradation

\section{INTRODUCTION}

A perovskite by definition is a material with the same crystal structure as $\mathrm{CaTiO}_{3}, \mathrm{BaTiO}_{3}, \mathrm{CaSiO}_{3}$, or $\mathrm{SrTiO}_{3}$. Perovskite mineral was discovered in the Ural Mountains, Russia, in 1839. A German mineralogist and crystallographer named Gustav Rose received the samples from Alexander Kämmerer-a Russian mineralogist. Rose did a lot of work on the determination of the properties of perovskite, and taking that into account, he named this mineral after Lev Perovski, who was a Russian politician and mineralogist (Park et al., 2016; Katz, 2020; Etgar, 2016). Typically, perovskites are binary metal oxides with a general formula $\mathrm{ABO}_{3}$, where $\mathrm{A}$ cation can be lanthanide, alkaline, or alkaline earth cation, and B cation is a metallic element with 3-, 4-, or 5-day configuration (Arandiyan et al., 2018). Perovskite and perovskite-related materials have emerged as an important new class of materials due to their fascinating physicochemical properties such as thermal stability, electron mobility, and redox behavior (Zhu et al., 2015; Arandiyan et al., 2018), and their versatile applications in catalysis, water splitting, solar cells, optical devices, and superconductors (Khalesi et al., 2008a; Khalesi et al., 2008b).

An ideal perovskite structure has an $\mathrm{ABO}_{3}$ stoichiometry and a cubic crystal structure (Figure 1). The cubic cell is composed of a three-dimensional framework of corner-sharing $\mathrm{BO}_{6}$ octahedra. The B-site cation is a transition metal element (Kubacka et al., 2012). The A-site cation occupies the 12 coordinate position formed by the $\mathrm{BO}_{6}$ network and often consists of an alkaline earth metal element 


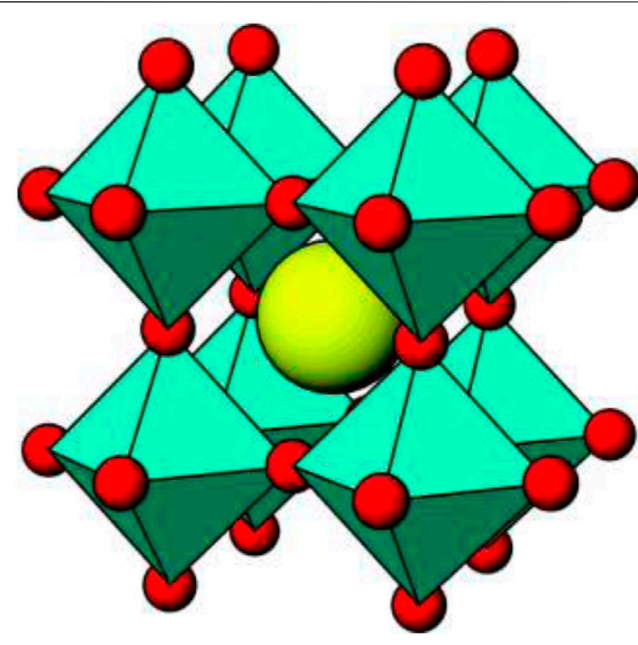

FIGURE 1 | Ideal cubic perovskite structure for $\mathrm{ABO} 3$ (cyan, $\mathrm{BO}_{6}$ units; yellow, A atoms; Kubacka et al. (2012).

or a rare earth element. With comparison to the ideal cubic perovskite $\mathrm{ABO}_{3}$, perovskite-related structures arise from the loss of one or more of the symmetry operator in the cubic structure and exhibit lattice distortion to varying degrees, thereby resulting in a nonideal structure of the crystal phases such as orthogonal, rhombohedral, tetragonal, monoclinic, and triclinic phases. Although primitive cubic is the idealized structure, the differences in radii between both cations can in fact distort the structure. This normally involves tilting of the $\mathrm{BO}_{6}$ units (octahedral tilting; Kong et al., 2019). This distortion is created in the crystalline structure as perovskites adopt a wide range of different composition by partially substituting either $\mathrm{A}$ or $\mathrm{B}$ cation of the same or different valences, resulting in a general formula $\mathrm{A} 1-\mathrm{xAx}$ ' $\mathrm{B} 1-\mathrm{yB}$ ' $\mathrm{yO} 3 \pm \delta$, where “+” denotes oxygen excess and "-" denotes oxygen deficiency. It is important to note that both $\mathrm{A}$ and $\mathrm{B}$ or either offers great flexibility with regard to tailoring and tuning of the physicochemical properties (Zhang et al., 1990; Zhu et al., 2015; Torregrosa-Rivero et al., 2017; Arandiyan et al., 2018). For example, Gade et al. (2018) studied the photocatalytic efficiency in $\mathrm{ALaTi}_{2} \mathrm{O}_{6}$, where $\mathrm{A}$ is $\mathrm{Na}, \mathrm{Ag}$, or $\mathrm{Cu}$. This new class of material efficiently and effectively mineralized the Congo red dye, 4-chlorophenol, and $4-4^{\prime}$-bis (2 sulfostyryl) biphenyl used as model pollutants (Gade et al., 2018). The stability of the perovskite is summarized by the Goldschmidt tolerance factor, $t=(\mathrm{rA}+\mathrm{rO}) / \sqrt{2}(\mathrm{rB}+\mathrm{rO})$, where $r A, r_{B}$, and $r_{O}$ are the, respective, radii of $A, B$, and oxygen ions. For the perovskite structure, the Goldschmidt tolerance factor lies between 0.76 and 1.13 (Zhu A. et al., 2014; Acharya et al., 2015; Kumar et al., 2019).

The diverse composition of emerging pollutants in water suggests that no single method of water treatment can be termed universal. This necessitates the exploration of newer water treatment methods and the tailoring of these methods to certain segments of wastewater. In response to this water treatment challenge, advanced oxidation processes (AOPs) have been developed as an effective technology to remove persistent organic pollutants from wastewater. AOPs are based on in situ generation of radicals that nonselectively react with most organics and are able to degrade highly recalcitrant compounds (Brillas and Martínez-Huitle, 2015; Garcia-Segura and Brillas, 2017; Peleyeju and Arotiba, 2018; Umukoro et al., 2018). This review is in addition to the existing body of knowledge around AOPs for water treatment. It is however distinct as it focuses on the application of perovskites in advanced oxidation processes related to water treatment. The so-called first-generation photocatalysts such as $\mathrm{TiO}_{2}, \mathrm{SnO}$, and $\mathrm{ZnO}$ have the limitations of wide bandgap and thus only UV responsive. The second-generation photocatalysts $\left(\mathrm{WO}_{3}, \mathrm{Fe}_{2} \mathrm{O}_{3}\right.$, and $\mathrm{Cu}_{2} \mathrm{O}$ ) have the challenge of low quantum yield due to their rapid electron-hole recombination and poor stability (Kong et al., 2019). Perovskite and perovskite-related materials are considered as third-generation photocatalysts which form a stable structure and solid solution with several ranges of metal ions to achieve the appropriate band engineering for photoelectrocatalytic applications (Yang et al., 2009; Kong et al., 2019). Emphasis will be on photocatalysis and electrochemically advanced oxidation systems such as electrocatalysis and photoelectrocatalysis, with perovskites as the semiconductor. Prior to the discussions of the applications of the perovskites in water treatment, brief accounts on synthesis and types of this interesting material are provided.

\section{GENERAL SYNTHESIS METHODS FOR PEROVSKITES}

Perovskites are usually formed at elevated temperature because from their composition, perovskite oxides are compounds consisting of two or more simple oxides having high melting points (Arandiyan et al., 2018). The approach to synthesize perovskite oxide must be selected according to the specific application, specific demands of activity, and selectivity as these depend on the arrangement of atoms within its surface (Lim et al., 2019). For example, the solid-state synthesis method is commonly used to prepare perovskite in the pure form due to the availability of impurity-free precursors, and they find application in electronics. The downside of the solid-state synthesis approach is that it requires annealing at high temperature for a long time and frequent intermediary grindings which results in poor homogeneity as well as difficulty in controlling the particle size. Thus, problem arises when perovskites from solid-state methods are subjected to surface-related studies.

Since this review focuses on photocatalysis and photoelectrocatalysis, the methods discussed are those related to improved porosity, to achieve high surface area, etc. Efforts have been made by researchers in synthesizing perovskites at low temperatures with improved porosity (Labhasetwar et al., 2015). To overcome the homogeneity drawback of solid-state methods and to achieve nanocrystalline phase, reproducibility, and pure powder, several groups have focused on wet chemistry methods such as citrate sol-gel method, precipitation method, electrospinning technique, ultrasonic method, hydrothermal method, and microwave-assisted synthesis methods. Wet 
chemistry methods are characterized by their simplicity, reduced sintering time, mass production, high level of repeatability, lower temperature (than solid-state reaction), better flexibility in thin film-forming superior homogeneity, improved control of stoichiometry, purity, particle size, and a low industrialization implementation cost (Assirey, 2019). One of the challenges faced in the development of perovskite catalyst is obtaining the right structure and maintaining high surface area because of high calcination temperature employed sometimes during synthesis (Akinlolu et al., 2019). Hence, the choice of method of preparation is a top priority.

\section{Hydrothermal Method}

The hydrothermal method is a useful technique for synthesizing perovskites. This method depends on solubility of minerals in hot water under high pressure, and many syntheses of perovskites for catalytic purpose have been carried out with various advancements using this method. The hydrothermal method is useful in perovskite synthesis as the particle size and shape can be affected by controlling the reaction temperature, $\mathrm{pH}$, time, and concentration of reactants. Biasotto et al. (2011) hydrothermally synthesized bismuth ferrite (BFO) nanoparticles at a low temperature of $180^{\circ} \mathrm{C}$ within $1 \mathrm{~h}$. In comparison with solidstate reaction process, the authors recorded submicron crystallites of BFO with enhanced homogeneity. Met and group (Kostyukhin et al., 2019) synthesized $\mathrm{LaFeO}_{3}$ via a hydrothermal microwave-assisted synthesis at a relatively low temperature of $240^{\circ} \mathrm{C}$ and pressure of 60 bar. In the procedure, the precursors were mixed in deionized water with the addition of $\mathrm{KOH}$ gradually while stirring. The presence of microwave as the heating source assisted in an enhanced crystallization rate of nanoparticles. Gao et al. (2015) synthesized $\mathrm{BiFeO}_{3}$ using nitrates of bismuth and iron via a hydrothermal method. $\mathrm{KOH}$ was added as a mineralizer to assist in the coprecipitation of $\mathrm{Bi}^{3+}$ and $\mathrm{Fe}^{3+}$. The XRD result shows that a single-phase cube-like $\mathrm{BiFeO}_{3}$ was successfully synthesized. Also, the effects of reaction time, $\mathrm{KOH}$ concentration, and organic dispersant on the $\mathrm{BiFeO}_{3}$ particle morphology size were investigated. The prepared photocatalyst showed excellent photodegradation of methyl orange dye (MO) under visible light $(>420 \mathrm{~nm}$ ).

Additionally, hydrothermal technique has also been adopted for the preparation of doped perovskites as well as perovskitebased heterojunctions. For instance, Baeissa, 2016 synthesized gold-doped $\mathrm{NaNbO}_{3}$ through a hydrothermal method for photocatalytic degradation of malachite green dye. The morphology of sodium niobate was studied by changing the hydrothermal temperature from 100 to $250^{\circ} \mathrm{C}$. The XRD results reveal that all samples prepared at different temperature were of the perovskite structure. The hydrothermal temperature played an important role in the structure and surface area of the obtained sodium niobate as the temperatures at $100,150,200$, and $250^{\circ} \mathrm{C}$ led to photocatalysts with surface area of $7,9,13$, and $16 \mathrm{~m}^{2} / \mathrm{g}$, respectively. Wen et al. (2017) synthesized a novel $\mathrm{SrTiO}_{3} / \mathrm{BiOI}$ heterostructure photocatalyst through hydrothermal and facile chemical bath methods with the aid of ethylene glycol. The XRD pattern of $\mathrm{SrTiO}_{3}$ depicts a characteristic tetragonal structure with a cubic

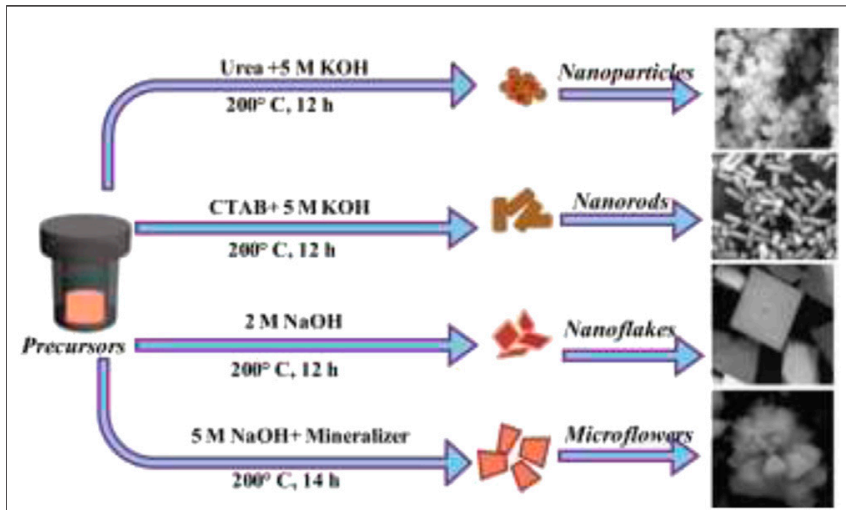

FIGURE 2 | Schematic illustration for tuning the morphology BFO nanostructures with different experimental conditions by the hydrothermal process (Remya et al., 2020).

$\mathrm{SrTiO}_{3}$ perovskite structure, and the morphology of $\mathrm{SrTiO}_{3}$ possesses nanosheets of irregular edges. It was also noticed that the $\mathrm{SrTiO}_{3}$ nanosheets fasten on the surface of $\mathrm{BiOI}$ nanoplates, forming a $\mathrm{SrTiO}_{3} / \mathrm{BiOI}$. Photocatalytic activity, photoluminescence, and electrochemical impedance spectroscopy analysis confirmed higher photo-induced charge separation efficiency possessed in $\mathrm{SrTiO}_{3} / \mathrm{BiOI}$ composites, which they attributed to an intimate contact between $\mathrm{SrTiO}_{3}$ and $\mathrm{BiOI}$.

These reports show that hydrothermal synthesis is ideal for the preparation of pristine perovskites as well as composites containing perovskites. However, the efficiency of the hydrothermal method is dependent on various modifications of experimental conditions such as temperature and solvents used in dissolution of precursor reagents. Remya and group (Remya et al., 2020) synthesized $\mathrm{BiFeO}_{3}$ via hydrothermal methods with different experimental conditions for the finetuning of the final product (Figure 2).

\section{Citrate Sol-Gel Method}

The citrate sol-gel method is usually used to prepare nanosized materials. Although its application is limited due to stability of its precursor system, it is difficult to control the chemical composition of complex oxides. The sol-gel procedure in aqueous medium uses inorganic salts and a chelating agent of carboxylic acid such as citric acid as a precursor. This technique has widely been used in making thin films with low temperature. Chu et al. (2018) reported a B site-deficient perovskite prepared via the classic sol-gel calcination method. In these methods, the nitrates of the metal ions were dissolved in deionized water, citric acid, and ethylene glycol to form a homogeneous solution at a certain $\mathrm{pH}$, calcination temperature, and time. The XRD pattern showed that pure perovskite was successfully formed. SEM images revealed that most of the nanoparticles are nonagglomerated due to low calcination temperature. The prepared photocatalyst displayed a good photocatalytic property. 


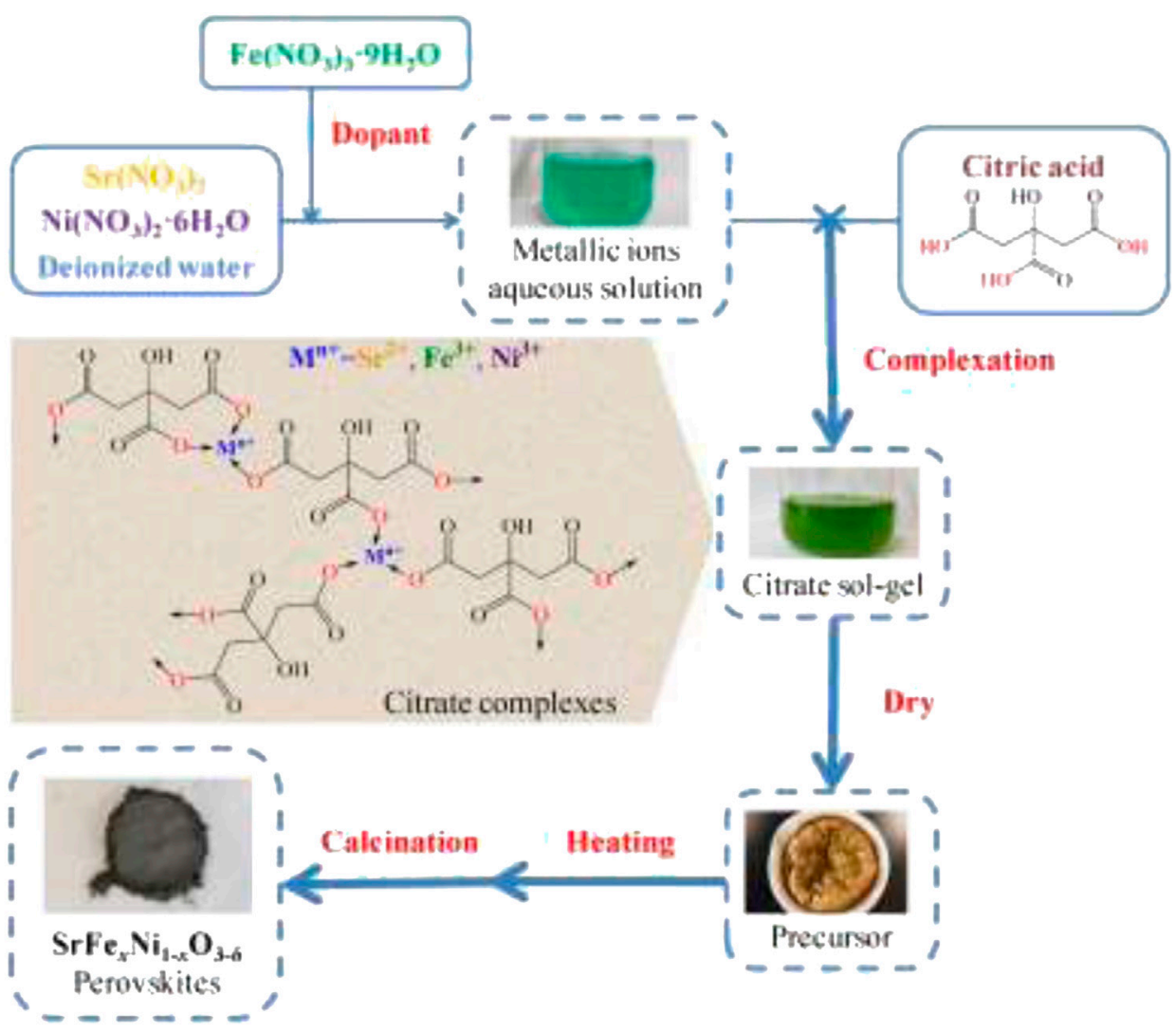

FIGURE 3 | Schematic diagram of the fabrication process of the $\mathrm{SrFe}_{x} \mathrm{Ni}_{1-\mathrm{x}} \mathrm{O}_{3^{-} \delta}$ perovskites (Zhang $\mathrm{Y}$. et al., 2019).

In another report, $\mathrm{LaMg}_{\mathrm{x}} \mathrm{Fe}_{\mathrm{x}-1} \mathrm{O}_{3-\delta}$ perovskite prepared via sol-gel route showed a formation of well-crystallized perovskite. $\mathrm{LaMgFe}_{3}$ and $\mathrm{LaMgFe}_{4}$ photocatalysts presented a particle size of around $100-150 \mathrm{~nm}$ with a well-defined size. The photocatalytic efficiency of $\mathrm{LaMgFe}_{4}$ was higher than that of other prepared catalysts owing to its smaller particle size distribution and higher surface area (Teresita et al., 2016). Zhang Y. et al. (2019) prepared $\mathrm{SrFe}_{\mathrm{x}} \mathrm{Ni}_{1 \mathrm{x}} \mathrm{O}_{3-\delta}(x=0,0.1,0.2$, $0.3,0.4$, and 0.5 ) via the citrate sol-gel method (Figure 3 ). They recorded their optimum catalyst with good electrocatalytic performance for water treatment was prepared at a reaction time of $120 \mathrm{~min}$, a calcination temperature of $700^{\circ} \mathrm{C}$, and Fe-doping content of $x=0.3$.

\section{Coprecipitation Method}

Coprecipitation occurs as a result of different cations in solution precipitating simultaneously, and this method encourages homogeneity of products. Coprecipitation plays a critical role in controlling the temperature, concentration, $\mathrm{pH}$, and solution homogeneity. Haron et al. (2017) prepared a nanostructured perovskite oxide such as $\mathrm{LaMO}_{3}(\mathrm{M}=\mathrm{Al}, \mathrm{Co}$, or Fe $)$ by the coprecipitation method. They observed a formation of singlephase nanocrystalline with high purity, larger surface areas, and porosity.
Djoudi reported a study on $\mathrm{LaAl}_{1-\mathrm{x}} \mathrm{Ni}_{\mathrm{x}} \mathrm{O}_{3-\delta}$ prepared via the coprecipitation method using $\mathrm{NaOH}$. They observed an increase in peak shift as the concentration of doping material increases, and crystallinity of all samples varies as the calcination temperature was adjusted. Therefore, the pure perovskite phase sample was calcined at $700^{\circ} \mathrm{C}$ for $6 \mathrm{~h}$ with no impurity. The morphology of the sample showed partial agglomeration, and interestingly, the material exhibited great electroactivity properties, which indicates a good electrocatalyst for oxygen reduction and evolution (Djoudi and Omari, 2015).

\section{PEROVSKITE OXIDE-BASED MATERIALS IN PHOTOCATALYSIS AND PHOTOELECTROCATALYSIS}

\section{Perovskite Materials in Photocatalysis}

In recent years, advanced oxidation processes (AOPs) have emerged to be efficient and effective methods for the treatment of wastewaters. They are utilized for the removal of organic pollutants during water treatment due to the generation and use of hydroxyl radicals as oxidizing species, which initiate other reactions for the degradation and possibly mineralization of organic pollutants. Among the AOPs, photocatalysis has 
attracted attention as a promising technique for solving environmental problems. Photocatalysis is a process that occurs when a semiconductor absorbs a photon of energy greater than its bandgap (the region between the electron-fill valance band and the empty conduction band of a semiconductor), and an electron is excited to the conduction band, thereby creating a hole in the valence band. The generation of the electrons could lead to oxidation and reduction reactions on the surface of the semiconductor (Umukoro et al., 2016). Semiconductors such as $\mathrm{TiO}_{2}, \mathrm{SnO}$, and $\mathrm{ZnO}$ are widely used as a catalyst in photocatalytic reactions. $\mathrm{TiO}_{2}$ has been widely applied in photocatalysis owing to its stability, low toxicity, low cost, and high oxidation efficiency. However, its rapid recombination of photogenerated electron-hole pairs and low absorption of visible light are shortcomings that necessitate the need for other materials that have narrower bandgap and wider range of wavelength of light absorption in the visible range, and high solar energy. A suitable photocatalyst should have the following characteristics: i) it should have a bandgap $\geq 1.2 \mathrm{eV}$ to provide energetic electrons and a bandgap $\leq 3.0 \mathrm{eV}$ to allow effective absorption of overlap with the solar spectrum; ii) its photogenerated charge carriers should be easily available for use with the electrolyte, and it should be resistant to photocorrosion (Ge et al., 2016; Kumar A. et al., 2020). Other beneficial factors include low cost, facile preparation method, and amenability to bandgap tuning. Perovskites fit into these characterizes to a large extent. The shortcomings of recombination and photocorrosion can be minimized by perovskite composites such as in doping and/or heterojunction formation. Table 1 shows some recent perovskites that found their application on photocatalysis for water treatment. The different classes of perovskites used in PC are discussed in the following sections.

\section{Lanthanum-Based Perovskites in Photocatalysis}

Lanthanum-based perovskites have raised interest as a result of their intriguing properties such as oxygen mobility, ionic conductivity, and excellent magnetic properties. For example, $\mathrm{LaFeO}_{3}$ had been proposed to be a significant material in photocatalytic areas because it exhibited several attention due to its properties such as narrow bandgap $\left(\mathrm{E}_{\mathrm{g}}=\right.$ $1.86-2.36 \mathrm{eV})$, more stability, and also environmental friendliness (Yahya et al., 2019). Thus, various synthesis approaches such as using template reagent and doping with other metals have been used to improve surface areas and enhance the charge transfer and light captivation through local surface plasmon resonance to improve its catalytic performance. For instance, Wang and group (Zhang W. et al., 2019) synthesized porous lanthanum-titanium $\mathrm{La}_{2} \mathrm{Ti}_{2} \mathrm{O}_{7}$ using $\mathrm{CTAB}$ as a template reagent through the sol-gel method toward the degradation of azophloxine dye. The authors observed that the presence of CTAB influenced the specific surface area and the crystallinity of the $\mathrm{La}_{2} \mathrm{Ti}_{2} \mathrm{O}_{7}$. The maximum number of hydroxyl radical was generated on the $\mathrm{La}_{2} \mathrm{Ti}_{2} \mathrm{O}_{7}$ sample obtained with $4 \mathrm{~g}$ of $\mathrm{CTAB}$, which degraded about $100 \%$ of the dye after $180 \mathrm{~min}$ from UV-Vis absorption analysis. The photocatalytic degradation efficiencies for the first and the fifth cycles are 100 and $91 \%$, respectively. The authors attributed this slight decline to the loss of fine $\mathrm{La}_{2} \mathrm{Ti}_{2} \mathrm{O}_{7}$ powder when taking solution samples for examination. This observation is consistent with one of the major challenges of photocatalysis-catalyst recovery. Also, in order to improve the photocatalytic performance of lanthanum-based perovskites, multiple complex or layered perovskite oxides containing lanthanum have been used. For example, Verduzco et al. (2018) synthesized a layered perovskite oxide $\mathrm{Sr}_{2.7-\mathrm{x}} \mathrm{Ca}_{\mathrm{x}} \mathrm{Ln}_{0.3} \mathrm{Fe}_{2} \mathrm{O}_{7-\delta}$ ( $\mathrm{Ln}=\mathrm{Nd}$ and $\mathrm{La}$ ) by a conventional solid-state reaction for degradation of methylene blue (MB) dye under solar and UV irradiation.

Varying the stoichiometry or doping of perovskite with a cation of different valence states can change the electronic structure, which dictates the electrical and optical properties (Zhang et al., 2010). The photocatalytic properties of $\mathrm{Sr}_{3.2-\mathrm{x}} \mathrm{Ca}$ ${ }_{x} \mathrm{La}_{0.8} \mathrm{Fe}_{1.5} \mathrm{Co}_{1.5} \mathrm{O}_{10-\delta}$ (Oliva et al., 2017) were studied by monitoring the degradation of methylene blue (MB) dye. This Ca-doped layered perovskite belonging to Ruddlesden-Popper (R-P) family exhibited increase in absorbance due to the creation of defects such as atomic dislocation induced by the replacement of Sr by Ca. It is worthy to note that the formation of these defects such as oxygen vacancies or trapping centers is suitable for photocatalysis because these oxygen vacancies diminish the rate of electron-hole recombination (Wu et al., 2016). As reported by Oliva et al. (2017), higher photocatalytic degradation was observed as the $\mathrm{Ca}$ content increased. The layered perovskites (SCLFCO sample) with $x=0.8$ produced a total degradation of $\mathrm{MB}(100 \%)$ after $150 \mathrm{~min}$ at a $\mathrm{pH}=6.0$, whereas the undoped sample with $x=0$ showed only a maximum degradation of $27 \%$ after $300 \mathrm{~min}$. The authors attributed this to the lower bandgap, the low level of agglomeration, and particle size. The authors also explained that the chemical reaction for the degradation was due to the presence of $\mathrm{Cl}^{-}$ion in $\mathrm{MB}$ molecule that balanced the charge with methyl group attached to a positive $\mathrm{N}^{+}$. So the presence of $\mathrm{Ca}^{2+}$ ion on the surface of the doped SCLFCO attracted $\mathrm{Cl}^{-}$in the $\mathrm{MB}$, thereby creating an unbalanced charge which facilitated the breaking of chemical bonds of the methyl groups attached to the chain of the MB molecule. Yang's group (Guan et al., 2020) immobilized $\mathrm{LaFeO}_{3}$ and $\mathrm{Au}$ nanoparticles on the $\mathrm{Cu}_{2} \mathrm{O}$ surface as a ternary composite photocatalyst for rhodamine $\mathrm{B}$ degradation. The composite demonstrated a far more photocatalytic degradation performance than bare $\mathrm{LaFeO}_{3}$ and $\mathrm{Cu}_{2} \mathrm{O}$. This avenue assists in facilitating the spatial separation of photo-induced electron hole. In another study, Ag nanoparticle was used to decorate $\mathrm{LaTiO}_{3}$ for the degradation of pesticide in water. The authors (Shawky et al., 2020) observed an improvement in the surface texture as observed from the morphological analysis. The composite demonstrated an enhancement in light absorption and reduced recombination rate as compared to the pure $\mathrm{LaTiO}_{3}$; as a result, complete degradation of atrazine pollutant within 40 min of irradiation was observed. Numerous reports have shown that incorporation or decoration of lanthanum-based perovskites with other metals or semiconductors results in 
TABLE 1 | Recent perovskites in photocatalysis for water treatment.

\begin{tabular}{|c|c|c|c|c|c|c|c|c|c|}
\hline Perovskite & $\begin{array}{l}\text { Co- } \\
\text { catalyst }\end{array}$ & $\begin{array}{l}\text { Light } \\
\text { source }\end{array}$ & Method & Pollutant & $\begin{array}{l}\text { Pollutant } \\
\text { conc }\end{array}$ & $\begin{array}{l}\text { Catalyst } \\
\text { conc }\end{array}$ & Time & $\%$ Removal & References \\
\hline $\mathrm{BiFeO}_{3}$ & N-rGO & $\begin{array}{l}\mathrm{Hg} \text { arc } \\
\text { lamp }\end{array}$ & - & Rhodamine B & 100 mg/L & 10 mg/L & $3 \mathrm{~h}$ & 98.7 & Dixit et al. (2020) \\
\hline $\mathrm{LaTiO}_{3}$ & $\mathrm{Ag}$ & $300 \mathrm{~W} \times \mathrm{Xe}$ & Hydrothermal & Atrazine & - & $1.2 \mathrm{~g} / \mathrm{L}$ & $40 \mathrm{~min}$ & 100 & Shawky et al. (2020) \\
\hline $\mathrm{SrTiO}_{3}$ & rGO & $450 \mathrm{~W} \times \mathrm{Xe}$ & Hydrothermal & Rhodamine B & $0.04 \mathrm{mg}$ & $0.01 \mathrm{~g}$ & - & 94.5 & $\begin{array}{l}\text { Rosy and Kalpana } \\
(2018)\end{array}$ \\
\hline $\mathrm{LaMnO}_{3}$ & $\mathrm{Ca}$ & $\begin{array}{c}25 \mathrm{~mW} \\
\mathrm{~cm}-2\end{array}$ & Hydrothermal & Methylene blue & 7 ppm & $0.07 \mathrm{~g} / \mathrm{L}$ & $360 \mathrm{~min}$ & 73 & Arabi et al. (2018) \\
\hline $\mathrm{CaSnO}_{3}$ & rGO & UV & $\begin{array}{l}\text { Microwave } \\
\text { irradiation }\end{array}$ & Methylene blue & 100 mg/L & $0.1 \mathrm{~g}$ & $150 \mathrm{~min}$ & 92 & $\begin{array}{l}\text { Venkatesh et al. } \\
\text { (2020b) }\end{array}$ \\
\hline $\mathrm{La}_{2} \mathrm{MnTiO}_{6}$ & - & $400 W$ & Sol gel & AB 113 & 50 mg/L & 30 mg/L & $120 \mathrm{~min}$ & 72 & Shirazi et al. (2020) \\
\hline $\mathrm{SmFeO}_{3}$ & $\mathrm{CuO}$ & $300 \mathrm{~W}$ & $\begin{array}{l}\text { Sol gel } \\
\text { calcination }\end{array}$ & $\begin{array}{l}\text { Rhodamine B } \\
\text { phenol }\end{array}$ & $\begin{array}{l}20 \mathrm{mg} / \mathrm{L} \\
20 \mathrm{mg} / \mathrm{L}\end{array}$ & $0.15 \mathrm{~g}$ & $120 \min$ & 9385 & $\begin{array}{l}\text { Behzadifard et al. } \\
\text { (2018) }\end{array}$ \\
\hline $\mathrm{BiFeO}_{3}$ & $\mathrm{BiOl}$ & - & Hydrothermal & - & 60 ppm & $0.12 \mathrm{~g} / \mathrm{L}$ & $136 \mathrm{~min}$ & - & $\begin{array}{l}\text { Bahmani et al. } \\
(2020)\end{array}$ \\
\hline $\mathrm{SrTiO}_{3}$ & $\mathrm{Ag} / \mathrm{Ag}_{3} \mathrm{PO}_{4}$ & $500 \mathrm{~W} \times \mathrm{e}$ & Hydrothermal & Tetracycline & 10 mg & $0.2 \mathrm{~g} / \mathrm{L}$ & $15 \min$ & 72 & Yu et al. (2020) \\
\hline $\mathrm{SrTiO}_{3}$ & $\mathrm{La}, \mathrm{Fe}$ & $150 \mathrm{~W}$ & Ball milling & Methyl orange & 5 ppm & $0.6 \mathrm{~g} / \mathrm{L}$ & $150 \mathrm{~min}$ & 96 & Abdi et al. (2020) \\
\hline $\mathrm{SrTiO}_{3}$ & $\mathrm{La}, \mathrm{Cr}$ & $300 \mathrm{~W}$ Xe & $\begin{array}{l}\text { Sol gel } \\
\text { hydrothermal }\end{array}$ & Tetracycline & 20 mg/L & 50 mg & 90 min & 83 & Jiang et al. (2019) \\
\hline $\mathrm{LaNiO}_{3}$ & $\mathrm{TiO}_{2}$ & $300 \mathrm{~W}$ Xe & Sol gel & $\begin{array}{l}\text { Methyl orange } \\
\text { ciprofloxacin }\end{array}$ & $\begin{array}{l}10 \mathrm{mg} / \mathrm{L} \\
10 \mathrm{mg} / \mathrm{L}\end{array}$ & $\begin{array}{l}100 \mathrm{mg} \\
50 \mathrm{mg}\end{array}$ & $\begin{array}{l}150 \mathrm{~min} \\
210 \mathrm{~min}\end{array}$ & 10054 & Chen C. et al. (2020) \\
\hline $\mathrm{BiBaFeO}_{3}$ & $\mathrm{Na}, \mathrm{K}$ & $250 \mathrm{~W}$ Xe & Sol gel & Methylene blue & 10 mg/L & 15 mg & $120 \mathrm{~min}$ & 65 & Haruna et al. (2020) \\
\hline $\mathrm{CaTiO}_{3}$ & $\begin{array}{l}\text { 2D/1Dg- } \\
\text { C3N4 }\end{array}$ & Sunlight & Hydrothermal & $\begin{array}{l}\text { Crystal violet } \\
\text { malachite }\end{array}$ & $\begin{array}{l}10 \mathrm{mg} / \mathrm{L} \\
10 \mathrm{mg} / \mathrm{L}\end{array}$ & 20 mg/L & $\begin{array}{l}180 \mathrm{~min} \\
90 \mathrm{~min}\end{array}$ & 99.7695 .02 & Chen X. et al. (2020) \\
\hline $\mathrm{LaCoO}_{3}$ & $\mathrm{Mn}, \mathrm{N}$ & $32 \mathrm{~W}$ & $\begin{array}{l}\text { Pechini-type } \\
\text { sol gel }\end{array}$ & Malachite green & 10 mg/L & 40 mg/L & $5.5 \mathrm{~h}$ & 80 & $\begin{array}{l}\text { Nakhostin Panahi } \\
\text { et al. (2020) }\end{array}$ \\
\hline $\mathrm{LaCoO}_{3}$ & $\mathrm{Ag}$ & - & Hydrothermal & Methylene blue & $\mathrm{N} / \mathrm{A}$ & $\mathrm{N} / \mathrm{A}$ & 10 min & 99 & $\begin{array}{l}\text { Jayapandi et al. } \\
\text { (2018) }\end{array}$ \\
\hline $\begin{array}{l}(\mathrm{NaBi}) \\
\mathrm{TiO}_{2}-\mathrm{BaTiO}\end{array}$ & $\mathrm{Ag}, \mathrm{N}-\mathrm{Ni}$ & $300 \mathrm{~W}$ & Solid state & Rhodamine B & 10 mg/L & $1 \mathrm{~g} / \mathrm{L}$ & $80 \mathrm{~min}$ & 92.4 & Xiao et al. (2020) \\
\hline $\mathrm{CsPbBr}_{3}$ & QD & $300 \mathrm{~W}$ & Precipitation & $\begin{array}{l}\text { Tetracycline } \\
\text { methyl orange }\end{array}$ & 10 mg/L & $100 \mathrm{mg}$ & $30 \mathrm{~min}$ & 7670 & Qian et al. (2020) \\
\hline $\mathrm{SrZrO}_{3}$ & $\mathrm{Sb}_{2} \mathrm{O}_{3}$ & $450 W$ & Solid state & Tetracycline & 10 ppm & 0.2 & $180 \min$ & 70 & $\begin{array}{l}\text { Huerta-Flores et al. } \\
\text { (2018) }\end{array}$ \\
\hline$\left[\mathrm{BaNiNbO}_{3}\right]$ & {$\left[\mathrm{KNbO}_{3}\right]$} & UV & Solid state & Methylene blue & 20 mg/L & $150 \mathrm{mg}$ & $120 \mathrm{~min}$ & 55 & Zhang et al. (2020) \\
\hline $\mathrm{CaTiO}_{3}$ & $\mathrm{Bi}_{12} \mathrm{O}_{17} \mathrm{Cl}_{2}$ & $300 \mathrm{~W}$ Xe & Hydrothermal & Tetracycline & $0.02 \mathrm{~mol} / \mathrm{L}$ & 50 mg & $30 \mathrm{~min}$ & 90.7 & Jiang et al. (2020) \\
\hline $\mathrm{LaFeO}_{3}$ & CA & $100 \mathrm{~W}$ & Gel combustion & Azo dye RB5 & 30 mg/L & $0.1 \mathrm{~g}$ & $80 \min$ & 100 & Yahya et al. (2019) \\
\hline $\mathrm{La}_{2} \mathrm{Ti}_{2} \mathrm{O}_{7}$ & CTAB & $20 \mathrm{~W}$ & Sol gel & Azophloxine & 40 mg/L & $600 \mathrm{mg}$ & $180 \mathrm{~min}$ & - & Zhang et al. (2019) \\
\hline $\mathrm{AgLaTi}_{2} \mathrm{O} 6$ & $\mathrm{Na}, \mathrm{Cu}$ & $25 \mathrm{~W}$ & Sol gel & Congo red IWW & $10-4,50 \mathrm{ml}$ & 50 mg & $\begin{array}{l}60 \mathrm{~min} \\
240 \mathrm{~min}\end{array}$ & 24 & Gade et al. (2018) \\
\hline $\mathrm{LaMnO}_{3}$ & - & Solar & Citrate sol gel & Methyl orange & 6.5 ppm & $\mathrm{N} / \mathrm{A}$ & $60 \min$ & 100 & $\begin{array}{l}\text { Rekavandi et al. } \\
\text { (2019) }\end{array}$ \\
\hline $\mathrm{CaTiO}_{5}$ & $G$ & 11 W UV & Solvothermal & Methyl orange & $\begin{array}{c}1 \times 10-4 \mathrm{M} \\
50 \mathrm{ml}\end{array}$ & $10 \mathrm{mg}$ & $36 \mathrm{~h}$ & $\mathrm{~N} / \mathrm{A}$ & Dong et al. (2020) \\
\hline $\mathrm{KTaO}_{3}$ & $\mathrm{~N}$ & $150 W$ & Solvothermal & Methylene blue & $1 \times 10-5 \mathrm{M}$ & $20 \mathrm{mg}$ & $360 \mathrm{~min}$ & $\begin{array}{c}\text { Complete } \\
\text { degradation }\end{array}$ & Rao et al. (2018) \\
\hline $\mathrm{MgTiO}_{3}$ & $\mathrm{MgFe}_{2} \mathrm{O}_{4}$ & UV & Sol gel & Acid black & 500 ppm & $0.1 \mathrm{~g}$ & $30 \mathrm{~min}$ & 67.9 & Kiani et al. (2019) \\
\hline $\mathrm{CaTiO}_{3}$ & $\mathrm{Li}, \mathrm{Ce}$ & UV & Sol gel & Methyl orange & 14 ppm & $26 \mathrm{mg}$ & $150 \mathrm{~min}$ & 90 & Mužina et al. (2020) \\
\hline $\mathrm{BiFeO}_{3}$ & LNR & Sunlight & Sol gel & Methyl orange & 10 ppm & $0.15 \mathrm{~g}$ & $3 \mathrm{~h}$ & 98.9 & Ridzuan et al. (2020) \\
\hline $\mathrm{SrSnO}_{3}$ & $\mathrm{ZrO}_{2}$ & UV & Pechini method & Azo dye & $10 \mathrm{mg} / \mathrm{L}$ & $60 \mathrm{mg}$ & $10 \mathrm{~h}$ & 98 & Honorio et al. (2020) \\
\hline $\mathrm{La}_{2} \mathrm{Ti}_{2} \mathrm{O}_{7}$ & HTAB & UV & Sol gel & Olfloxacin & 40 mg/L & $30 \mathrm{mg}$ & $30 \mathrm{~min}$ & 58.6 & Han et al. (2020) \\
\hline $\mathrm{BiFeO}_{3}$ & - & $100 \mathrm{~W}$ & Chemical route & Methylene blue & $10 \mathrm{mg} / \mathrm{L}$ & $20 \mathrm{mg}$ & N/A & $\mathrm{N} / \mathrm{A}$ & Verma et al. (2020) \\
\hline $\mathrm{LaFeO}_{3}$ & $\mathrm{Au}, \mathrm{Cu}_{2} \mathrm{O}$ & $200 \mathrm{~W}$ Xe & Sol gel & Rhodamine & 5 mg/L & $1 \mathrm{~g} / \mathrm{L}$ & $180 \mathrm{~min}$ & 88.4 & Guan et al. (2020) \\
\hline $\mathrm{BiFeO}_{3}$ & La & 500 W & Sol gel & Methylene blue & 15 mg/L & $1 \mathrm{~g} / \mathrm{L}$ & $2.20 \mathrm{~h}$ & 78.8 & $\begin{array}{l}\text { Kumar A. et al. } \\
(2020)\end{array}$ \\
\hline $\mathrm{LaMnO}_{3}$ & CTAB & - & Hydrothermal & Methylene violet & 15 ppm & $5 \mathrm{mg}$ & $315 \mathrm{~min}$ & 95 & $\begin{array}{l}\text { Priyatharshni et al. } \\
\text { (2020) }\end{array}$ \\
\hline
\end{tabular}

pronounced enhancement in the photocatalysis (Arabi et al., 2018; Yahya et al., 2019; Chen C. et al., 2020; Nakhostin Panahi et al., 2020).

\section{Non-Lanthanum-Based Perovskites}

The applications of other non-lanthanum-based perovskites in photocatalysis have been reported. The following sections discuss 
ferrite-based, titanate-based, tantalum, and other types of perovskites for photocatalysis.

\section{Ferrite-Based Perovskite in Photocatalysis}

Iron-based perovskites have the general formula $\mathrm{AFeO}_{3}$, where $\mathrm{A}$ is a metal ion like $\mathrm{Ca}, \mathrm{Sr}, \mathrm{Ba}, \mathrm{Bi}, \mathrm{La}, \mathrm{Gd}, \mathrm{Ga}$, or Y (Tang et al., 2011; Dhanasekaran and Gupta, 2012; Ramadan et al., 2013). Ironbased compounds could also adopt the $\mathrm{FeAO}_{3}$ structure, where A could be Ti (Gross-Sorokin et al., 2006; AlSalka et al., 2019). In this case, physical properties such as magnetism and/or ferroelectricity, which can be beneficial for the photocatalytic activity, are added to the material. Magnetism and/or ferroelectricity facilitate in extracting the photocatalyst from solution by an external magnet and also assist in the separation of the photogenerated charges.

Ferrite-based perovskites have proven to be promising materials for photocatalytic and photoelectrocatalytic applications in the field of environmental remediation. The interest and advantage of ferrite oxide could be attributed to its excellent properties such as narrow bandgap, nontoxicity, abundance of constituent element, low cost, and excellent electrical and catalytic properties (Liu et al., 2016). Ferritebased perovskites attract attention due to their exceptional magnetic and electronic properties. They have intrinsic electric dipole moment due to a distortion in their crystal structures, which promotes separation of photogenerated charges during the photoexcitation process (Chen et al., 2017; AlSalka et al., 2019).

Most of the iron-based perovskites exhibit bandgaps within the visible region of the solar spectrum. For instance, bismuth iron oxide $\mathrm{BiFeO}_{3}(\mathrm{BFO})$, a multi-ferroic member of the ironbased perovskites, is a typical case where simultaneously and spontaneously antiferromagnetic $(\mathrm{TN}=643 \mathrm{~K})$ and ferroelectric (TC 1123 K) order coexist well above room temperature (Sosnowska et al., 1992; Sati et al., 2015). $\mathrm{BiFeO}_{3}$ (BFO) with a rhombohedral distorted perovskite is a promising visible light responsive photocatalyst for organic pollutants degradation due to the suitable narrow bandgap $(2.2-2.8 \mathrm{eV})$, excellent chemical stability, as well as intrinsic electric polarization (Ramadan et al., 2013). Charge-transfer (CT) transitions and spectroscopic measurements of the dielectric function of $\mathrm{BiFeO}_{3}$ single crystal (Pisarev et al., 2009) showed a defect-free intrinsic bandgap of $\sim 3.0 \mathrm{eV}$ superimposed on a weak absorption band at $2.5 \mathrm{eV}$. This result signified the effect of defects and oxygen vacancies on the bandgap, and the shifting of the optical properties into the visible region. Electronic structure investigations have established the strongly hybridized nature of the valence band (Neaton et al., 2005; Clark and Robertson, 2007). However, some researchers reported that the photocatalytic activity of BFO was not impressive (Wang S. et al., 2016; Dixit et al., 2020), and they reported some drawbacks from $\mathrm{BFO}$ such as poor carrier mobility and rapid recombination of photogenerated electron-hole pairs. Based on these challenges, several strategies have been in place to improve its photocatalytic activity such as metal ion doping (Wang L. et al., 2016), heterostructure construction (Wang et al., 2017), structural control (Meng et al., 2016), and cocatalyst loadings (Behzadifard et al., 2018).
It has been recognized that metal ion doping assists in producing electron-hole trapping site which would probably accelerate the separation and transfer of the excited electron-hole pairs during the photocatalytic reaction (Wang S. et al., 2016; Dixit et al., 2020). Doping can also introduce surface defects such as oxygen vacancies by charge compensation arising between the dopant and the parent cation (Wang L. et al., 2016; Wang S. et al., 2016). Wang (Wang et al., 2017) studied the effects of oxygen vacancies induced by zirconium doping in bismuth ferrite for catalysis. The morphology features investigated by SEM and TEM showed the Zr-doped BFO with a smaller particle size of $50-150 \mathrm{~nm}$ significantly reduced aggregation as compared to the pristine $\mathrm{BFO}$. The incorporation of $\mathrm{Zr}$ into $\mathrm{BFO}$ was confirmed by XPS. They reported that the optical absorption of the $\mathrm{Zr}$-doped samples slightly shifted toward the shorter wavelength as opposed to the pristine $\mathrm{BFO}$ which has a strong absorption both in UV and visible light regions. A better photocatalytic performance in degradation of methyl orange (MO) using $2 \% \mathrm{Zr}-\mathrm{BFO}$ sample compared to the pure BFO and other $\mathrm{Zr}$ percentage loading samples was reported (Wang et al., 2017). Meng et al. (2016) studied the effect of the influence of lanthanum doping on photocatalytic properties of $\mathrm{BiFeO}_{3}$ for phenol degradation. The catalyst was prepared by a one-step facile sol-gel method using citric acid as the chelating agent. The gel was calcined at $500^{\circ} \mathrm{C}$ for $2 \mathrm{~h}$ and then at $600^{\circ} \mathrm{C}$ for $1 \mathrm{~h}$ in a muffle furnace. From the XRD result, the $\mathrm{BiFeO}_{3}$ structured was formed with the rhombohedral phase along with $\mathrm{Bi}_{25} \mathrm{FeO}_{40}$ impurity. As the wt\% loading of $\mathrm{La}$ doping increases, the characteristic peak of the impurity disappeared. The result inferred that appropriate amount of $\mathrm{La}^{3+}$ doping can suppress the generation of impurity. SEM result also showed that $15 \mathrm{wt} \% \mathrm{La}$-doped $\mathrm{BiFeO}_{3}$ assisted to decrease the catalyst particle size. The bandgap of the samples was studied using the Kubelka-Munk (K-M) formula. The authors suggested that La doping narrowed the bandgap.

Several studies have been done on ferrite-based perovskites, and majorities of them are in combination with other metals, nanomaterials, and other semiconductors with a purpose of extending light absorption range, retarding the electron hole recombination, and boosting the electron mobility toward efficient charge separation to achieve an excellent photocatalytic degradation of pollutants in water (Behzadifard et al., 2018; Malathi et al., 2018; Yahya et al., 2019; Bahmani et al., 2020; Dixit et al., 2020; Diyan et al., 2020; Haruna et al., 2020; Kumar P. et al., 2020).

\section{Titanate-Based Perovskites in Photocatalysis}

Titanate-based perovskite $\left(\mathrm{MTiO}_{3}\right)$ as a material has been explored in several applications. According to Alammar et al. (2015), they are promising materials for photocatalytic processes because of their excellent resistance to photocorrosion and high thermal stability. Ternary titanate-based perovskites such as $\mathrm{CaTiO}_{3}, \mathrm{BaTiO}_{3}$, and $\mathrm{SrTiO}_{3}$ are wide bandgap titanate perovskite semiconductors with interesting electronic, optical, and magnetic properties (Alammar et al., 2015). 
The preparation of titanate-based perovskite via the solid-state method often contains agglomerated particles of different sizes, morphologies, and impurities. Therefore, other methods where size, shape, and purity can be improved are favored. Titanatebased perovskites have offered applications in the area of photocatalytic hydrogen production and hydrocarbon reforming (Hbaieb et al., 2017). According to Zhang et al. (2007), the perovskite structure consisting of oxygen octahedral, such as $\mathrm{TiO}_{6}$, seems to play an important role for active photocatalysts, and the band edge positions, width of the conduction band, bandgap, and migration of photogenerated charge carriers as well as the photocatalytic activities are closely related to the distortion and the connectivity of the $\mathrm{MO}_{6}\left(\mathrm{M}=\mathrm{Ti}^{4+}, \mathrm{Nb}^{5+}\right.$, and $\left.\mathrm{Ta}^{5+}\right)$ octahedra in perovskite titanates, niobates, and tantalates.

Titanate-based perovskites are reported to be photoactive materials, but their performance is impeded sometimes because of their wide bandgaps. However, titanate-based perovskites (such as $\mathrm{SrTiO}_{3}$ perovskite) exhibit good photostability and are thus applied in $\mathrm{H}_{2}$ production, solar cells, etc. Alammar et al. (2015) investigated the application of $\mathrm{MTiO}_{3}(\mathrm{M}=\mathrm{Ca}, \mathrm{Sr}$, and $\mathrm{Ba})$ on the degradation of methylene blue using UV light. They reported that nitrogen-doped $\mathrm{SrTiO}_{3}$ showed good photocatalytic properties under visible light irradiation due to the formation of new states in the bandgap, allowing absorption of visible light. Huang S.-T.et al. (2014) studied the photocatalytic activity of $\mathrm{SrTiO}_{3}$ (STO) synthesized by the autoclave hydrothermal method under the alkaline concentration and time. In photodegradation of the model pollutant-crystal violet $(\mathrm{CV})$ dye, STO prepared with $3 \mathrm{M}$ $\mathrm{NaOH}$ for $72 \mathrm{~h}$ at $130^{\circ} \mathrm{C}$ showed best photocatalytic performance with UV light. In tailoring the optical and photocatalytic properties of $\mathrm{SrTiO}_{3}, \mathrm{Lu}$ et al. (2017) successfully incorporated bismuth ferrite into it, forming a structure $\mathrm{Sr}_{1-\mathrm{x}} \mathrm{Bi}_{\mathrm{x}} \mathrm{Ti}_{1-\mathrm{x}} \mathrm{Fe}_{\mathrm{x}} \mathrm{O}_{3}$. The synergetic effect resulted in more substantial visible light absorption, narrow bandgap, and enhanced photocatalytic performance. This study shows the possibility of tuning the bandgap of titanate-based perovskites into the visible light region. Lakhera et al. (2018) synthesized a visible light-responsive titanate-based perovskite by preparing a composite of $\mathrm{TiO}_{2}$ and $\mathrm{NiTiO}_{3}$ for photocatalytic degradation and hydrogen production activity. The photocatalytic activity of the nanocomposite was investigated by the photodegradation of rhodamine $\mathrm{B}$ dyes and tetracycline. With different calcination temperatures, the samples behaved differently. The optimized sample NT@750C nanocomposite displayed the highest degradation activity for $\mathrm{RhB}$ with about $75 \%$ total degradation within $2 \mathrm{~h}$ and nearly $58 \%$ degradation of tetracycline in $2 \mathrm{~h}$ with visible light. The total organic carbon (TOC) removal for both pollutants was lower than the respective decolorization rate, which is an indication of intermediate formation. The reusability test results for $\mathrm{RhB}$ dye showed that the photocatalyst can be reused for up to three cycles consecutively without major lost in the photocatalytic activity. In another study, Kiani et al. (2019) reported that a facile method was used to prepare magnesium titanate with magnesium ferrite nanocomposite as a support to improve the photocatalytic activity in degrading azo dyes. As a result of the heterostructure formed, the holes migrated to the valence band of $\mathrm{MgFe}_{2} \mathrm{O}_{4}$, while the electrons in the conduction band (CB) of $\mathrm{MgFe}_{2} \mathrm{O}_{4}$ migrated to the $\mathrm{CB}$ of $\mathrm{MgTiO}_{3}$, enabling an efficient charge separation and low recombination rate, hence allowing room for more charges to participate in redox reaction. Therefore, the photodegradation efficiency of the nanocomposite $\mathrm{MgTiO}_{3}-\mathrm{MgFe}_{2} \mathrm{O}_{4}$ increased about $30 \%$ relative to $\mathrm{MgTiO}_{3}$. Combination power of microstructure and heterojunction techniques in a quest to remould the inherent wide bandgap and enhance its visible light absorption capacity and photocatalytic performance cannot be down played. A multishelled cube structure of the $\mathrm{CaTiO}_{3}-\mathrm{Bi}_{12} \mathrm{O}_{17} \mathrm{Cl}_{2}$ heterostructure was synthesized by Jiang et al. (2020) for degradation of tetracycline in water. They observed a greater percentage of tetracycline degradation within a short period with the multishelled hollow cube $\mathrm{CaTiO}_{3}-\mathrm{Bi}_{12} \mathrm{O}_{17} \mathrm{Cl}_{2}$ heterostructure. They attributed the achievement to the larger surface area exhibited by the composite which led to more active sites than those participated in the redox reaction. There was a reduction of bandgap from 3.51 to $2.61 \mathrm{eV}$, thereby enhancing the absorption and utilization of visible light irradiation. The photochemical properties of the prepared samples which include photocurrent response, electrochemical impedance spectroscopy (EIS), photoluminescence spectra (PL), and linear sweep voltammetry (LSV) showed that the heterostructured photocatalyst exhibited an excellent photostability, preferable electron-hole pair separation and longer lifetime, less charge migration resistance, and highest electric current densities.

Several researchers have reported titanate-based perovskite with heterostructure and co-doping. A majority of them have demonstrated an excellent photocatalytic performance as compared to their bare samples, and this is due to reduced bandgaps and efficient migration of charge pairs, hence reduced recombination rate which produces great catalytic activity within the redox reaction (Rosy and Kalpana, 2018; Jiang et al., 2019; Abdi et al., 2020; Chen X. et al., 2020; Dong et al., 2020; Han et al., 2020; Mužina et al., 2020; Tomar et al., 2020; Xiao et al., 2020; Yao et al., 2020; Yu et al., 2020). For instance, Abdi recorded 96\% photodegradation of methyl orange within $150 \mathrm{~min}$ with $\mathrm{Fe}-\mathrm{La}$-doped $\mathrm{SrTiO}_{3}$ nanoparticle as compared to $5 \%$ from bare $\mathrm{SrTiO}_{3}$ (Abdi et al., 2020). In addition, these heterostructures contribute in generating more $\mathrm{h}^{+}$and superoxide $\mathrm{O}_{2}$, which are crucial oxidizing species involved in the catalytic system.

\section{Tantalum and Other Perovskite-Based Materials in Photocatalysis}

Tantalum-based perovskites $\left(\mathrm{MTaO}_{3}\right)$ have received attention as a new class of material. They have been explored greatly in the area of water splitting. Kudo and Kato have carried out several studies on tantalum-related materials (Kato and Kudo, 1998; Kato and Kudo, 2001; Kudo et al., 2000). Tantalum-based perovskites $\left(\mathrm{MTaO}_{3}\right)$ have also found applications in photocatalysis. Li and Zang (2011) prepared La-doped $\mathrm{NaTaO}_{3}$ via the hydrothermal method for the degradation of salfranine $\mathrm{T}$ dye under $\mathrm{UV}$ irradiation. The $\mathrm{NaTaO}_{3}$ : $\mathrm{La}$ 
nanocube structure showed higher photocatalytic activity than the undoped. Usually narrow bandgap indicates convenient excitation from the valence band to the conductor band. Therefore, the authors attributed the higher catalytic activity observed on the doped material to the narrow bandgap it exhibited.

In the quest to improve the photocatalytic activity in perovskite, anion doping has been found attractive in improving the photocatalytic activity under visible light. Liu et al. (2011) synthesized $\mathrm{N}$-doped $\mathrm{NaTaO}_{3-\mathrm{x}} \mathrm{N}_{\mathrm{x}}$ via the onestep hydrothermal method for the degradation of methyl orange. Doping with nonmetals has been shown to increase the catalytic activity of material as it narrows the bandgap and creates oxygen vacancies. The photocatalytic decolorization efficiency of $\mathrm{N}$-doped $\mathrm{NaTaO}_{3}$ was enhanced more than that of undoped because the interstitial nitrogen moved to the local state below the conduction band, and therefore excitation to the CB from the local state was convenient as a result of the "add on shoulder" on the $\mathrm{N}$-doped $\mathrm{NaTaO}_{3}$. They recorded complete decolorization within $14 \mathrm{~h}$ irradiation of sunlight at $\mathrm{pH} 4$ and COD removal percentage of $95.21 \%$ under the same conditions.

$\mathrm{N}$-doped potassium tantalate perovskite has also been used for the photocatalytic degradation of dye (Rao et al., 2018). The authors recorded reduction of bandgap and also extension of absorption of light from the UV region to the visible region which accelerates the photocatalytic activity. Modak and Ghosh (2014) successfully synthesized $\mathrm{N}$ (p-type) and $\mathrm{F}$ (n-type) doping in $\mathrm{NaTaO}_{3}$ under visible light. Co-doping with $\mathrm{N}$ and $\mathrm{F}$ resulted in the formation of charge compensation and the isoelectronic system on $\mathrm{NaTaO}_{3}$. There was a reduction in bandgaps and visible light active material as a result of doping with $\mathrm{N}$ and $\mathrm{F}$, which improved the photocatalytic activity. Apart from doping, the formation of heterojunction has also been reported for visible light photocatalytic applications. $\mathrm{WO}_{3}$-wrapped $\mathrm{NaTaO}_{3}$ prepared through a facile hydrothermal method was used to degrade tetracycline (Qu et al., 2015). An optimum percentage of $60.88 \%$ was recorded by the sample $\mathrm{NaTaO}_{3} / \mathrm{WO}_{3}$ which the authors attributed to an effective separation of the photogenerated electron-hole as well as the expansion of the absorption edge to the visible region due to the heterojunction structure.

Some other types of perovskites that have found applications on photocatalysis are discussed below. Huerta-Flores et al. (2018) synthesized the $\mathrm{SrZrO}_{3}-\mathrm{Sb}_{2} \mathrm{O}_{3}$ heterostructure for photocatalytic degradation of pharmaceutical compound. The heterostructure was successfully constructed using the impregnation method and was confirmed by XRD and SEM analyses. Results showed that they exhibited a weaker photoluminescence PL activity than $\mathrm{Sb}_{2} \mathrm{O}_{3}$ and $\mathrm{SrZrO}_{3}$, which is an indication that there was adequate charge separation and mobility in the interface of $\mathrm{SrZrO}_{3}-\mathrm{Sb}_{2} \mathrm{O}_{3}$, hence a minimized recombination rate. The open circuit potential (OCP) was used to evaluate the stability of the samples. The heterostructure exhibited good photostability because the presence of $\mathrm{SrZrO}_{3}$ inhibited the oxidation of $\mathrm{Sb}_{2} \mathrm{O}_{3}$. The higher amount of electron accumulated in the conduction band in the heterostructure was evident because the change in the OCP negative value from dark to light was higher. It was also recorded that $\mathrm{Sb}_{2} \mathrm{O}_{3}$ induced a rapid electron transfer to the solution, which was effective in avoiding the charge carrier recombination, thereby increasing the use of electron-hole pairs in the redox reaction. Results from the Nyquist plot showed a smaller arc radius for $\mathrm{Sb}_{2} \mathrm{O}_{3}$ and $\mathrm{SrZrO}_{3}-\mathrm{Sb}_{2} \mathrm{O}_{3}$ than the large semi-circle from $\mathrm{SrZrO}_{3}$ material. The decrease in the arc radius indicates a faster interfacial charge transfer. The authors summarized that as a result of diminished electron-hole recombination in the $\mathrm{SrZrO}_{3}-\mathrm{Sb}_{2} \mathrm{O}_{3}$ heterostructure, there was an increased availability of electron-hole separation which led to enhanced photodegradation of tetracycline.

Alkaline earth perovskite stannates such as $\mathrm{ZnSnO}_{3}, \mathrm{CaSnO}_{3}$, $\mathrm{SrSnO}_{3}$, and $\mathrm{BaSnO}_{3}$ have been widely used as photocatalysts. These materials have been found to be interesting for a number of potential applications in industry, such as components of dielectric ceramics; multifunctional signal sensors to detect temperature, humidity, and gas; as negative electrode active materials for long-life energy storage applications, and in the fabrication of ceramic boundary-layer capacitors (Zhang et al., 2006; Zhang et al., 2007; Fang et al., 2009). $\mathrm{SrSnO}_{3}$ has been explored and also proven to be an effective photocatalyst owing to its powerful oxidation and reduction capabilities. However, it is associated with large bandgap and a high recombination rate of photogenerated electron-hole pairs. Therefore, the applications of its heterostructured composites have attracted attention in recent years. For instance, Venkatesh et al. (2020a) synthesized a heterostructure $\mathrm{rGO}-\mathrm{SrSnO}_{3}$ nanocomposite via hydrothermal methods. The authors recorded $97 \%$ methylene blue degradation and $80.66 \%$ for pure $\mathrm{SrSnO}_{3}$. The optical property showed that a wide absorption band was identified at 220-270 $\mathrm{nm}$ for pure and rGO-SrSnO 3 composite, respectively. They recorded a reduced bandgap after incorporating rGO from 4.2 to $3.75 \mathrm{eV}$. Reduced graphene oxide has been an excellent electron acceptor with quick electron transport kinetics, and by that, the support of $\mathrm{SrSnO}_{3}$ with rGO assisted in transferring the photo-induced electron to participate in the reaction, thereby leading to enhanced photocatalytic performance. Zhang et al. (2020) synthesized $\left[\mathrm{KNbO}_{3}\right]_{0.9^{-}}\left[\mathrm{BaNi}_{0.5} \mathrm{Nb}_{0.5} \mathrm{O}_{3-\delta}\right]$ perovskite via a solid phase reaction method for methylene blue degradation. KBNNO perovskite has a bandgap of $1.39 \mathrm{eV}$, which is much smaller than that of the parent perovskite $\mathrm{KNO}$. Incorporation of $\mathrm{Ni}^{2+}$ and $\mathrm{K}^{+}$encourages oxygen vacancies and charge compensation, respectively. The photocatalytic degradation efficiency of KBNNO was $55 \%$ in $120 \mathrm{~min}$. They concluded that the catalyst loading and dye concentration played a crucial role in the photocatalytic efficiency. Due to the octahedral tilting in the crystalline network of $\mathrm{SnO}_{6}$, this distortion plays an important role in the migration of photogenerated charge carriers in $\mathrm{SrSnO}_{3}$, $\mathrm{CaSnO}_{3}$, and $\mathrm{BaSnO}_{3}$ for photocatalytic degradation of pollutants (Honorio et al., 2020). Honorio et al. (2020) synthesized $\mathrm{SrSnO}_{3}$ with $\mathrm{ZrO}_{2}$ as a supporting semiconductor for photocatalytic degradation of a textile azo dye pollutant. Honorio discovered from SEM analysis that $\mathrm{SrSnO}_{3}$ was uniformly dispersed on $\mathrm{ZrO}_{2}$ which infers higher activity as a result of $\mathrm{SrSnO}_{3}$ active phase even in a smaller amount. Therefore, they recorded 63 and $98 \%$ degradation at time 2 and $10 \mathrm{~h}$, respectively. But, the doping 
TABLE 2 | Recent perovskites in photoelectrocatalysis for water treatment.

\begin{tabular}{|c|c|c|c|c|c|c|c|c|c|c|}
\hline Perovskite & Cocatalyst & $\begin{array}{l}\text { Light } \\
\text { source }\end{array}$ & Method & Pollutant & Substrate & $\begin{array}{l}\text { Pollutant } \\
\text { conc }\end{array}$ & $\begin{array}{l}\text { Catalyst } \\
\text { conc }\end{array}$ & $\begin{array}{l}\text { Time, } \\
\min \end{array}$ & $\begin{array}{c}\% \\
\text { Removal }\end{array}$ & Ref \\
\hline $\mathrm{BiFeO}_{3}$ & $\mathrm{Sm}, \mathrm{Pd}$ & $\begin{array}{l}300 \text { W, Xe } \\
\text { lamp }\end{array}$ & Conventional sol-gel & $\begin{array}{l}\text { Methyl orange, } \\
\text { phenol }\end{array}$ & FTO & 5 mg/L & $0.3 \mathrm{~g}$ & 120 & 8750.1 & $\begin{array}{l}\text { Wang L. et al. } \\
\text { (2016) }\end{array}$ \\
\hline $\mathrm{SrTiO}_{3}$ & $\mathrm{TiO}_{2}$ & $\begin{array}{l}300 \mathrm{~W}, \mathrm{Xe} \\
\text { lamp }\end{array}$ & $\begin{array}{l}\text { Hydrothermal/ } \\
\text { anodization }\end{array}$ & Methylene blue & $\mathrm{Ti}$ & $\mathrm{N} / \mathrm{A}$ & N/A & 20 & 99.93 & $\begin{array}{l}\text { Huang J.-R. } \\
\text { et al. (2014) }\end{array}$ \\
\hline $\mathrm{BiFeO}_{3}$ & $\mathrm{TiO}_{2}-\mathrm{NT}$ & $\begin{array}{l}500 \text { W, Xe } \\
\text { lamp }\end{array}$ & $\begin{array}{l}\text { Citric sol-gel/ultrasonic } \\
\text { immersion }\end{array}$ & Rhodamine & $\mathrm{Ti}$ & 20 mg/L & $\mathrm{N} / \mathrm{A}$ & 150 & 100 & $\begin{array}{l}\text { Zhu A. et al. } \\
(2014)\end{array}$ \\
\hline $\mathrm{LaFeO}_{3}$ & $\mathrm{SrTiO}_{2}$ & $\begin{array}{l}420 \mathrm{~nm} \\
\text { LED }\end{array}$ & $\begin{array}{l}\text { Ultrasonic spray } \\
\text { pyrolysis }\end{array}$ & NO & FTO & 400 ppb & $0.1 \mathrm{~g}$ & N/A & 40 & $\begin{array}{l}\text { Zhang et al. } \\
(2017)\end{array}$ \\
\hline
\end{tabular}

of $\mathrm{SrSnO}_{3}$ with $\mathrm{ZrO}_{2}$ did not significantly affect their bandgaps. They attributed this to be the presence of Sn(ll) having lower binding energy may have occupied the inter-band states below the conduction band of Sn(IV). Some studies have been carried out on Tin-based perovskites for photocatalysis which have yielded excellent catalytic performance (Wang et al., 2009; Junploy et al., 2013; Wang et al., 2014).

\section{Photoelectrocatalysis}

Photocatalysis has been widely utilized, and it is an important route for the degradation of organic waste. Its efficiency strongly relies on the catalyst. This technique has prominent advantages, including low cost and no secondary pollution. However, it has some drawbacks such as electron-hole pair recombination and catalyst recovery. Electrochemical oxidation localizes the semiconductor in the form of an electrode or substrate. Thus, the degradation of the organic pollutants occurs at the electrode surface or close to the electrode surface (hydroxyl radical in the bulk solution). This approach solves the catalyst recovery problem in photocatalysis. This electrochemical approach, however, requires high voltage and is prone to oxygen evolution, and the process is limited by mass transfer (Malpass et al., 2010; Sirés et al., 2014; Brillas and MartínezHuitle, 2015; Kusmierek and Chrzescijanska, 2015; Umukoro et al., 2017; Wang et al., 2018). The quest for improved techniques led to the emergence of photoelectrochemical oxidation or photoelectrocatalytic (PEC) processes. PEC is an electrolytic system containing a semiconductor-based anode that is simultaneously subjected to light illumination and a constant bias potential to the anode $\left(\mathrm{E}_{\text {anod }}\right.$ ), a constant cell potential $\left(\mathrm{E}_{\text {cell }}\right)$, or a constant anodic current density $\left(\mathrm{j}_{\text {anod }}\right)$. This process promotes the extraction of photo-induced $\mathrm{e}^{-\mathrm{CB}}$ by the external electrical circuit, thereby yielding an efficient separation of the $\mathrm{e}^{-\mathrm{CB} / \mathrm{h}+}$ vB pairs (Daghrir et al., 2012; Georgieva et al., 2012; Sirés and Brillas, 2012; Bessegato et al., 2015; Meng et al., 2015). The prevention of charge recombination promotes the photocatalytic efficiency of the anode and thus the acceleration of organic oxidation. The excitation of the anodic semiconductor and prolonged separation increases the lifetime of the hole so as to have more opportunities to either directly oxidize the organic pollutants adsorbed on the photoanode surface or indirectly react with absorbed water to form more hydroxyl radicals. Another advantage of PEC is the ease of recovery of photocatalyst after usage and possibility of multiple cycles of treatment. A myriad of semiconductor materials such as $\mathrm{TiO}_{2}$, $\mathrm{ZnO}, \mathrm{WO}_{3}$, and $\mathrm{BiVO}_{4}$ have been used as photoanodes in PEC. Another class of semiconductor used in PEC is perovskites. As seen in photocatalysis, their recent trend is to use visible light as the photoexcitation source for the anode.

\section{Perovskite in Photoelectrocatalysis for Water Treatment}

Perovskites have been extensively used in photocatalysis. In the area of photoelectrocatalysis (PEC), however, most applications of perovskites are in the energy sectors such as water splitting ( $\mathrm{Ni}$ et al., 2007; Bin Adnan et al., 2018; Phoon et al., 2018) and solar cells (Muñoz-Gil et al., 2018; Fan et al., 2020). The application of perovskite in PEC for water treatment is still at its infancy. This review seeks to capture the recent application of perovskites in PEC and thus provide a valuable resource for materials, perovskites, and environmental research communities. Reports on PEC for water treatment are shown in Table 2 and reviewed in the following paragraphs. The chemistry of catalyst (perovskites) improvement strategies is similar to that of those explained earlier. Owing to the need to fabricate an anode (usually by depositing the semiconductor), different synthesis and electrode preparation methods peculiar to PEC are expected.

The first task in the application of perovskites in photoelectrocatalytic removal of organic pollutants in water is to understand the electrochemical and photoelectrochemical behaviors of the perovskites. To get such information, the perovskites have to be fabricated into an electrode. One of the common substrates for the deposition of perovskites for PEC application is the fluorine-doped tin oxide glass (FTO). For example, Fermin and coworkers studied the photoelectrochemical properties of $\mathrm{LaFeO}_{3}$ nanoparticles by pasting an adhesive film of $\mathrm{LaFeO}_{3}$ (along with other diluents) on a FTO coated glass (Celorrio et al., 2014). Although this work was not on water treatment, valuable data such as photocurrent responses obtained from this work are necessary characterizations that inform the potential applicability of the perovskites for PEC water treatments. With the use of a similar electrode preparation strategy, Zhang carried out a robust study on the photoelectrochemical behavior of heterostructured perovskite of the $\mathrm{LaFeO}_{3}-\mathrm{SrTiO}_{3}$ composite on FTO glass for NO removal (Zhang et al., 2017). The electrode was characterized along with the control electrodes of pristine $\mathrm{LaFeO}_{3}(\mathrm{LFO})$ and 


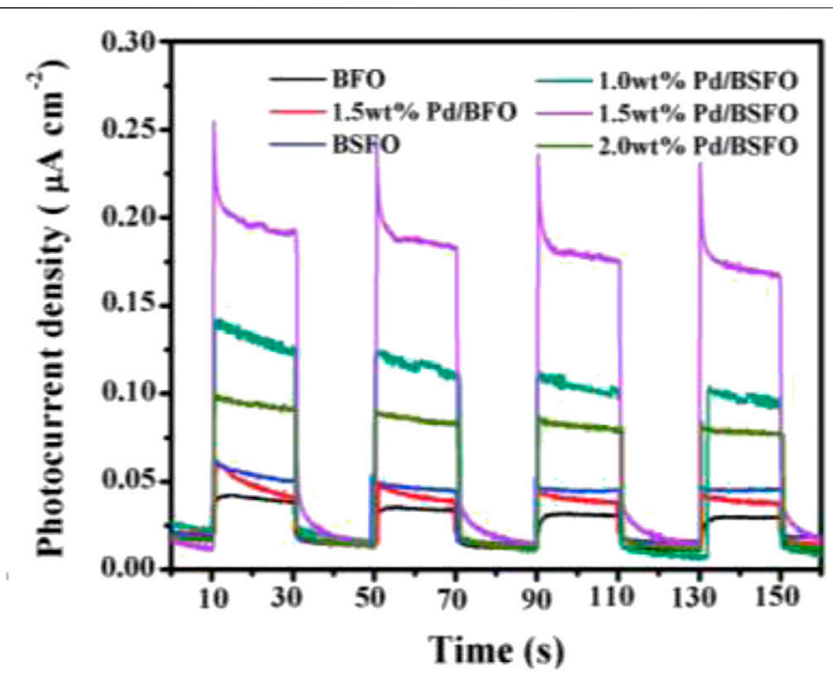

FIGURE 4 | Photocurrent action spectra of the prepared photocatalyst samples (Wang S. et al., 2016).

$\mathrm{SrTiO}_{3}$ (STO). While all the photoanodes showed good photoelectric responses, the composite (LFO-STO) showed very pronounced response, indicating that heterojunction greatly promotes the separation of photo-induced electron-hole pairs and leads to the improved catalytic reaction rate. The authors concluded that the improved catalytic activity is due to the broad visible light harvest, enlarged surface area, and a suppressed surface charge recombination that emanated from the perfectly matched $\mathrm{LaFeO}_{3}$ and $\mathrm{SrTiO}_{3}$ interface and facile charge transfer. Wang S. et al. (2016) also carried out photoelectrochemical studies to investigate the effect of a $\mathrm{Pd}$ cocatalyst and samarium doping in bismuth ferrite (BFO). Accordingly, the authors recorded a higher photocurrent response in $\mathrm{Pd} / \mathrm{BSFO}$ (BSFO $=$ Sm-doped $\mathrm{BFO}$ ) samples than in BFO, Pd/BFO, and BSFO. They concluded that photocatalytic analysis and electrochemical analysis such as photocurrent response as shown in Figure 4 demonstrated that the combination of Pd loading and Sm doping could significantly promote the separation of photogenerated electron-hole pairs in the $\mathrm{Pd} / \mathrm{BSFO}$ sample, thereby improving the photocatalytic activities.

As demonstrated by Arotiba and coworkers, such a photocurrent response from a photoanode can give a measure of how effective the electrode will be when used for PEC degradation (Umukoro et al., 2018; Orimolade et al., 2019; Orimolade et al., 2020; Orimolade and Arotiba, 2020).

One of the earliest work where a perovskite based photoanode was prepared and used for the PEC degradation of an organic pollutant is the work of (Zhu A. et al., 2014). The authors prepared $\mathrm{TiO}_{2}$ nanotubes $\left(\mathrm{TiO}_{2}-\mathrm{NT}\right)$ by anodic oxidation of titanium sheet and then deposited the $\mathrm{BiFeO}_{3}$ nanoparticles from its precursor on the $\mathrm{TiO}_{2}-\mathrm{NTs}$ via an ultrasonicimmersion strategy to form the $\mathrm{BiFeO}_{3} / \mathrm{TiO}_{2}-\mathrm{NT}$ s photoanode. The electrodes were extensively characterized by UV-vis diffusereflectance spectra, surface photovoltage, photoluminescence,

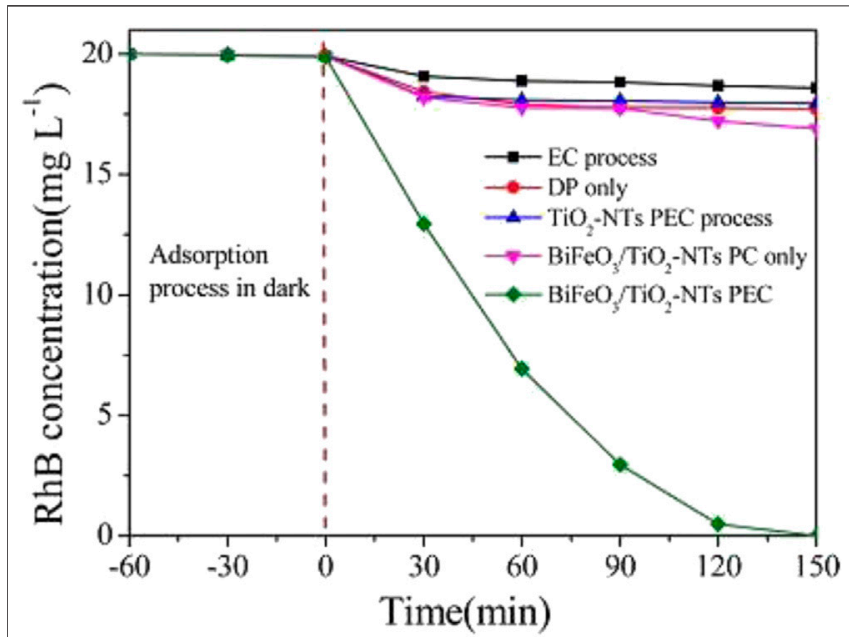

FIGURE 5 | RhB concentration varying with time through different degradation processes. PC, photocatalytic process; EC, electrochemical oxidation. Note: label "b" is from the original author reproduced with permission (Zhu J. et al. (2014).

electrochemical impedance spectroscopy etc. As shown in Figure 5 with the applied bias potential of $0.6 \mathrm{~V}$, the photoanode displayed a pronounced efficiency as compared to photocatalysis and electrochemical analysis. This is in agreement with the electrochemical impedance that the photoanode $\mathrm{BiFeO}_{3} /$ $\mathrm{TiO}_{2}$-Nts possessed a faster charge transfer across the electrode surface to the $\mathrm{Ti}$ substrate. These results point to a marked improvement in the photo-electrochemical properties of the $\mathrm{BiFeO}_{3} / \mathrm{TiO}_{2}-\mathrm{NTs}$ over $\mathrm{TiO}_{2}$-NTs. These improvements were attributed to ease of charge transfer between the two materials, the ferroelectric properties of $\mathrm{BiFeO}_{3}$ and the enhancement of charge separation. The $\mathrm{BiFeO}_{3} / \mathrm{TiO}_{2}-\mathrm{NTs}$ was used in the degradation of rhodamine $\mathrm{B}$ dye. $\mathrm{A}$ degradation of nearly $100 \%$ was achieved at the $\mathrm{BiFeO}_{3} / \mathrm{TiO}_{2}$-NTs photoanode after $150 \mathrm{~min}$. This was significantly higher than when other techniques such as electrochemical oxidation, direct photolysis and photocatalysis process were employed. The schemes suggested by the authors for the electrode, bandgap alignment and schematic pathways are presented in Figure 6. From the diagram, the formation of heterostructure assisted in the formation of appropriate Fermi level, the application of bias potential channelled the electrons generated from the conduction band of $\mathrm{BiFeO}_{3}$ to the conduction band of $\mathrm{TiO}_{2}$ NTs. The separated, photogenerated electrons reacted with the surface chemisorbed $\mathrm{O}_{2}$ to generate the strong oxidative species $\mathrm{O}^{2-}$, which combines with $\mathrm{H}^{+}$from solution to form $\mathrm{H}_{2} \mathrm{O}_{2}$. Finally, accumulated electrons in the counter electrode can react with $\mathrm{H}_{2} \mathrm{O}_{2}$ to generate $\mathrm{OH}$. This effective charge separation attributes to an excellent oxidation and reduction of the pollutants.

The positive coupling effect of combining $\mathrm{TiO}_{2}$ and other semiconductors is considered as an efficacious approach to promote $\mathrm{TiO}_{2}$ reactive properties. This enables the photogenerated charge carriers to migrate to the heterostructured interface to retard recombination. 


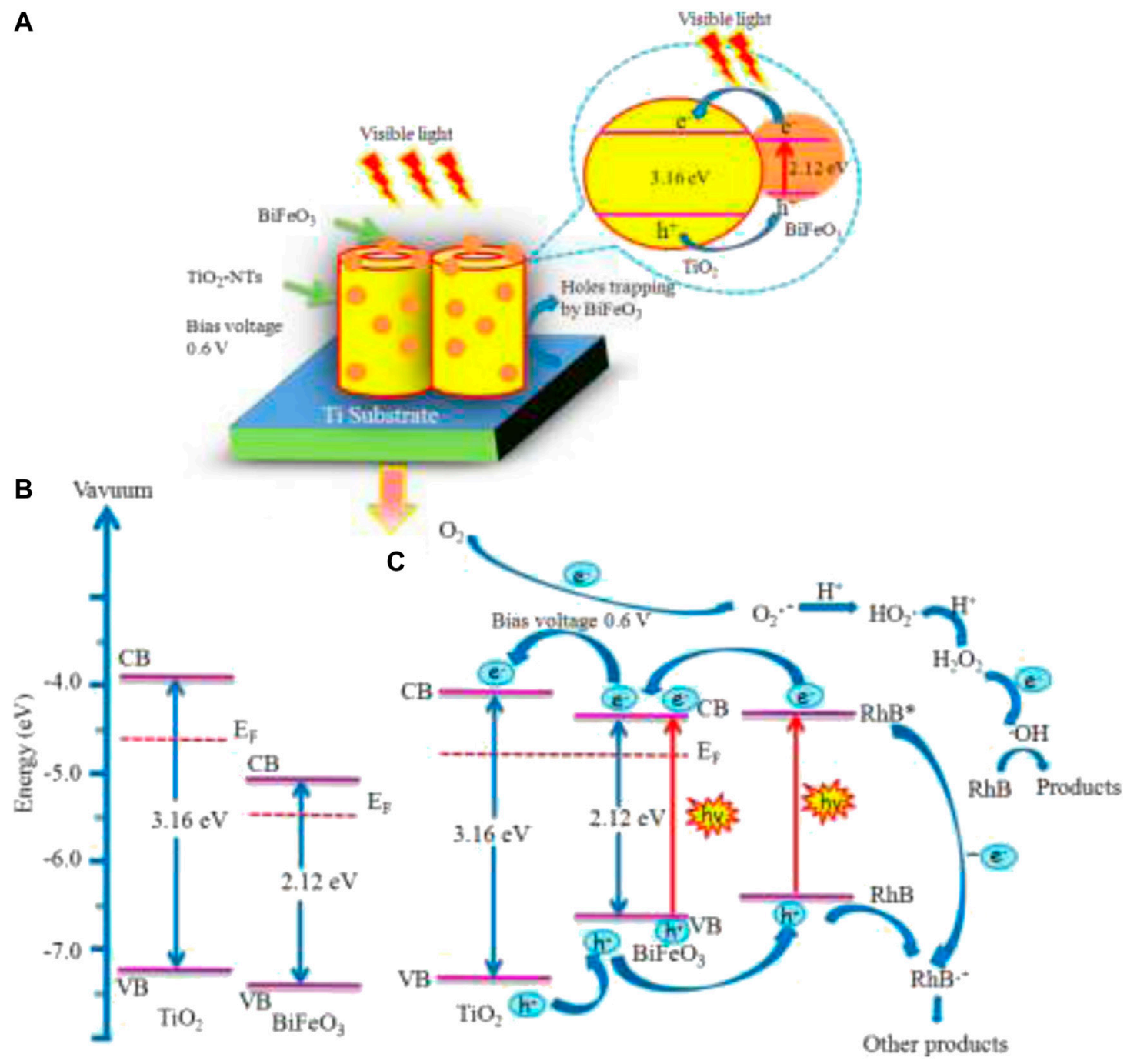

FIGURE 6 | (A) Cartoon diagram of the photogenerated electron generation, separation, and transfer path in $\mathrm{BiFeO}_{3} / \mathrm{TiO}_{2}-\mathrm{NTS}_{\mathrm{S}}$ upon visible-light excitation. (B) Conduction band, valence band, and Fermi-level positions of independent n-type $\mathrm{TiO}_{2}$ and n-type $\mathrm{BiFeO}$. (C) $\mathrm{Schematic}$ pathways of PEC degradation of RhB over $\mathrm{BiFeO}_{3} / \mathrm{TiO}_{2}-\mathrm{NT}$ s under a bias of $0.6 \mathrm{~V}$ applied onto the composite electrode (Zhu A. et al., 2014).

Huang J.-R.et al. (2014) constructed a heterostructured nanotube with $\mathrm{TiO}_{2} / \mathrm{SrTiO}_{3}$ for PEC degradation of methylene blue (MB) dye. The photocurrent response among all the prepared catalyst TSr3 (TNT in $\operatorname{Sr}(\mathrm{OH})_{2}$, $30 \mathrm{~min}$ hydrothermal time) showed the highest peak current, and it is twice as large as TNT2 $\left(\mathrm{TiO}_{2}\right.$ nanotube on Ti substrate). Their photocurrent response is such that when light is turned off, they returned instantly to zero; hence, the author concluded that the heterostructure composites under UV light can significantly promote the photogenerated electron/hole separation. The PEC degradation peak value was in good agreement with the rate constant $\mathrm{K}$ with the optimal sample TSr3. The MB percentage degradation and rate constant were $99.93 \%$ and $0.38492 \mathrm{E}^{-4} \mathrm{~min}^{-1}$, respectively. The authors attributed the result to be as a result of the positive cooperation of the high-reactive $\mathrm{TiO}_{2}\{001\}$ facet with $\mathrm{TiO}_{2} / \mathrm{SrTiO}_{3}$ heterostructured interface which strongly inhibited the photogenerated electron/hole recombination.

\section{Effect of $\mathrm{pH}$, Initial Concentration, and Catalyst Loadings of Perovskites in Photocatalysis and Photoelectrocatalysis \\ Effect of $p H$}

The $\mathrm{pH}$ of a solution influences the surface charge and protonation of the functional groups in a catalyst. It also promotes the efficiency and the performance of the process. Haruna et al. (2020) studied the $\mathrm{pH}$ of the solution for the degradation of $10 \mathrm{mg} / \mathrm{L}$ methylene blue using $\mathrm{Bi}_{0.85}$ ${ }_{\mathrm{x}} \mathrm{M}_{\mathrm{x}} \mathrm{Ba}_{0.15} \mathrm{FeO}_{3}(\mathrm{M}=\mathrm{Na}, \mathrm{K}$ and $\mathrm{x}=0,0.1)$ at $\mathrm{pH} \mathrm{3,pH} \mathrm{7,} \mathrm{and}$ $\mathrm{pH}$ 11. The observed improved photodegradation at $\mathrm{pH} 7$ and $\mathrm{pH}$ 
11 of doped and undoped catalyst was attributed to the interaction of the highly negative oxide species and the anion which influenced the surface charge of the photocatalyst. Another study shows the degradation of tetracycline at $\mathrm{pH} 3, \mathrm{pH} 5.60$, and $\mathrm{pH} 10$ using tungstendoped $\mathrm{BaTiO}_{3}$. The authors recorded the degradation rate of 90 and $80 \%$ for $\mathrm{pH} 10$ and $\mathrm{pH} 5.60$, respectively, after $3 \mathrm{~h}$ irradiation and $43 \%$ at $\mathrm{pH} 3$. They concluded that increasing $\mathrm{OH}$ ions on catalyst surface promoted more $\mathrm{OH}^{-}$radicals which participated in the redox reactions (Demircivi and Simsek, 2019). Depending on the nature of the pollutant and the photocatalyst, the degradation efficiency varies with $\mathrm{pH}$ of the solution, hence the need to detect the optimum conditions that are favorable at any given time. Simsek et al. (2020) studied the effect of $\mathrm{pH}$ in photocatalysis and photoFenton for the degradation of caffeine using $\mathrm{LaFeO}_{3}$. They observed that the photocatalyst performed optimally at natural $\mathrm{pH} 6.5$ compared with $\mathrm{pH} 3$ and $\mathrm{pH} 10$. According to Yao, the effect of $\mathrm{pH}$ and degradation of pollutant varies, and it is controversial (Haruna et al., 2020; Yao et al., 2004).

\section{Effect of Initial Concentration of Pollutants}

The increase in pollutant concentration could decrease the penetration of light into the solution for photocatalytic activity, thereby causing turbidity and opaqueness. Yahya et al. (2018) investigated the effect of initial concentration of humic acid using $\mathrm{LaFeO}_{3}$. They observed the photocatalytic removal in the order of $98,90,85$, and $86 \%$ for $10,20,30$, and $40 \mathrm{~g} / \mathrm{L}$, respectively. It shows that at lowest initial concentration of humic acid, the photocatalytic activity was at its best. Therefore, they concluded that at a high pollutant dosage, the penetration of light needed to travel to the active site to activate the photodegradation was blocked, resulting in few active sites and poor photocatalytic activity. Also, a similar result was obtained by Pelin, where the degradation of tetracycline solution with an initial concentration of 5,20 , and $40 \mathrm{mg} / \mathrm{L}$ showed a degradation rate of 93,80 , and $47 \%$, respectively (Demircivi and Simsek, 2019). Increase in turbidity, which can be due to high initial pollutant concentration is expected to reduce the efficiency of photoelectrocatalytic degradation of pollutants with perovskite-based photoanodes. This is because of insufficient light reaching the photoanode owing to poor penetration or scattering just as it is observed in photocatalysis. The issue of turbidity is not restricted to the pollutant concentration alone. Thus, for practicality, the process of simple filtration or sedimentation to remove suspended solids may precede PEC to improve the delivery of light onto the electrode or the catalyst.

\section{Effect of Catalyst Loadings}

Usually, at lower catalyst dosage, there are few active sites available for photodegradation, and at higher catalyst loadings, there are agglomeration, high turbidity, and scattering effects which lower the degradation efficiency in photocatalysis (Yahya et al., 2018; Yahya et al., 2020).
Behzadifard et al. (2018) investigated the effect of $\mathrm{CuO}(10$ wt\%) $\mathrm{SmFeO}_{3}$ composites for degradation of $10 \mathrm{mg} / \mathrm{L}$ rhodamine dye. They reported that the degradation rate of rhodamine increased with increasing catalyst loading from 0.05 to $0.15 \mathrm{~g}$; however, at $0.20 \mathrm{~g}$, the performance dropped, which they attributed to agglomeration and decrease in light penetration. It is therefore crucial to obtain the optimum value of catalyst loadings for cost-effectiveness and better photocatalytic performance.

\section{BANDGAP POSITIONS AND CHARGE TRANSFER MECHANISM OF PEROVSKITE OXIDES IN PHOTOCATALYSIS AND PHOTOELECTROCATALYSIS}

Bandgap calculation, tuning, and alignment are important in the characterization and in the prediction of the photocatalytic and photoelectrocatalytic efficiency of perovskite oxides (and other semiconductors) in water treatment. There are several ways of calculating band edge positions such as electronegativity-based calculation, density functional theory (DFT), the Mott-Schottky plot, dependence of photovoltage on $\mathrm{pH}$, and photocurrent-potential measurement (Zhang and Jaroniec, 2018). Some band edge potentials of selected perovskite oxides discussed in this review are shown in Figure 7. Mukherjee et al. (2018) highlighted the effect of bandgap on photocatalytic improvement by the preparation of a composite of BFO and reduced graphene oxide (RGO). The conduction band $(\mathrm{CB})$ and valence band $(\mathrm{VB})$ edge potentials suggest band bending which arises in the equilibration of the Fermi level with the increase in the space region of the composite. The increase in the space region of the BFO-RGO composite resulted in the negative shift in the band edge potential, which facilitated the charge carrier concentration and consequently increased the chances of faster electron transfer, suppressed recombination, and better photoelectrocatalytic degradation (see Figure 8). In another report, Wang S. et al. (2016) explored the effect of rare earth $(\mathrm{Sm})$ doping and noble $(\mathrm{Pd})$ cocatalyst doping in $\mathrm{BiFeO}_{3}$. The flat band potential measurement was calculated using the Mott-Schokkty plot. Doping of bismuth ferrite with foreign atoms in their $\mathrm{A}, \mathrm{B}$, or $\mathrm{O}$ sites of the $\mathrm{ABO}_{3}$ lattice has been proven to be an effective route to improving its photocatalytic properties (Mukherjee et al., 2018). From the band diagram in Figure 9, as reported by Wang L. et al. (2016), the hole could react with $\mathrm{H}_{2} \mathrm{O}$ on the surface to generate $\mathrm{OH}$ for oxidation reaction because the $\mathrm{VB}$ potential of $1.5 \mathrm{wt} \%$ $\mathrm{Pd}-\mathrm{BSFO}$ composite $(+2.35 \mathrm{eV})$ is positive enough when compared to $-\mathrm{OH} / \cdot \mathrm{OH}(+2.27 \mathrm{~V}$ vs $\mathrm{NHE})$ as opposed to the $\mathrm{CB}$ potential of $1.5 \mathrm{wt} \% \mathrm{Pd}-\mathrm{BSFO}(+0.27 \mathrm{eV})$ which is less negative than the potential $\mathrm{E}^{\mathrm{o}}\left(\mathrm{O}_{2} / \mathrm{O}_{2}{ }^{\circ}\right)(-0.046 \mathrm{~V}$ vs $\mathrm{NHE})$. Doping with rare earth metal served as an electron trapping specie to separate the photogenerated electron-hole from recombination, thereby promoting efficient charge carrier separation and consequently encouraging excellent 


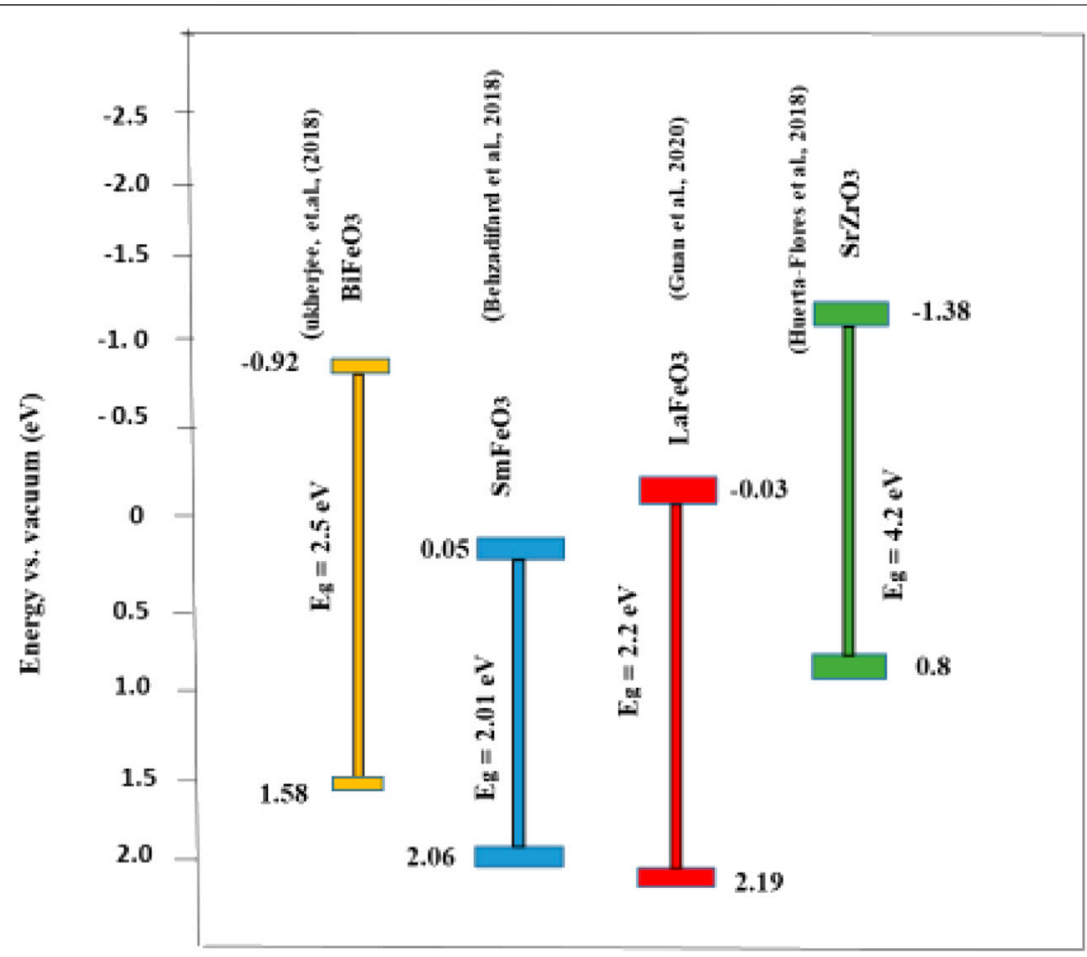

FIGURE 7 | Band positions of some perovskite oxide-based materials in photocatalytic and photoelectrocatalytic treatment of water.

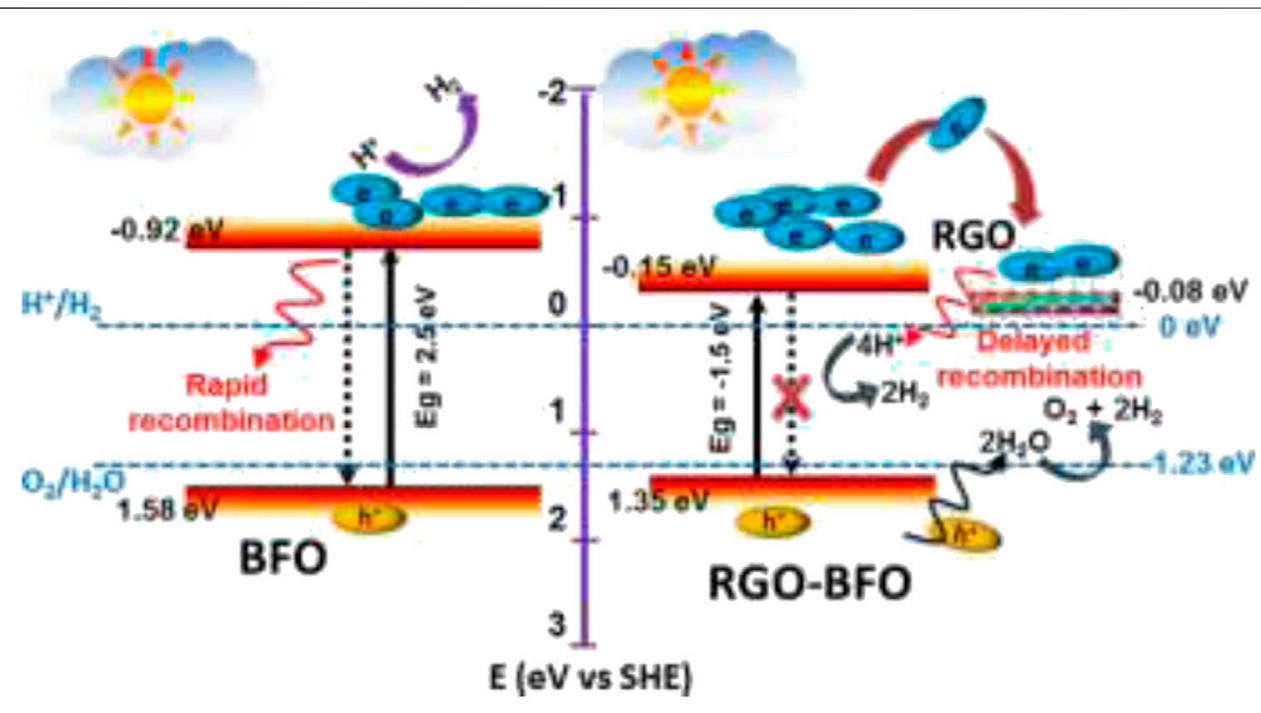

FIGURE 8|Schematic representation of the proposed mechanism of photocatalysis of BFO and RGO-BFO reproduced with permission (Mukherjee et al. (2018)).

photocatalytic activity. Behzadifard et al. (2018) studied the photocatalytic degradation of rhodamine and phenol. The band edge potentials were calculated using electronegativity methods. From the calculations, the $\mathrm{VB}$ and $\mathrm{CB}$ potentials for $\mathrm{CuO}$ were 1.97 and $0.65 \mathrm{eV}$ and those of $\mathrm{SmFeO}_{3}$ were 2.06 and $0.05 \mathrm{eV}$, respectively. Owing to the low negative $\mathrm{CB}$ potential value of $\mathrm{SmFeO}_{3}$, adsorbed oxygen cannot be converted to $-\mathrm{O}_{2}$. On the other hand, the $\mathrm{CB}$ potential of $\mathrm{CuO}$ is more positive than $\mathrm{SmFeO}_{3}$; hence, electrons can migrate to the $\mathrm{CB}$ of $\mathrm{CuO}$. In other words, $\mathrm{CuO}$ is acting as electro acceptor and is able to trap the electrons. Also, the $\mathrm{CB}$ potential of $\mathrm{CuO}(0.65 \mathrm{eV})$ is positive enough and closer to the potential for $\mathrm{O}_{2} / \mathrm{H}_{2} \mathrm{O}_{2}(+0.695 \mathrm{eV})$, and the electrons are able to react with adsorbed oxygen to produce $\mathrm{H}_{2} \mathrm{O}_{2}$ and 
A $\cdot \mathrm{OH}+\mathrm{MO} \rightarrow$ Degradation products

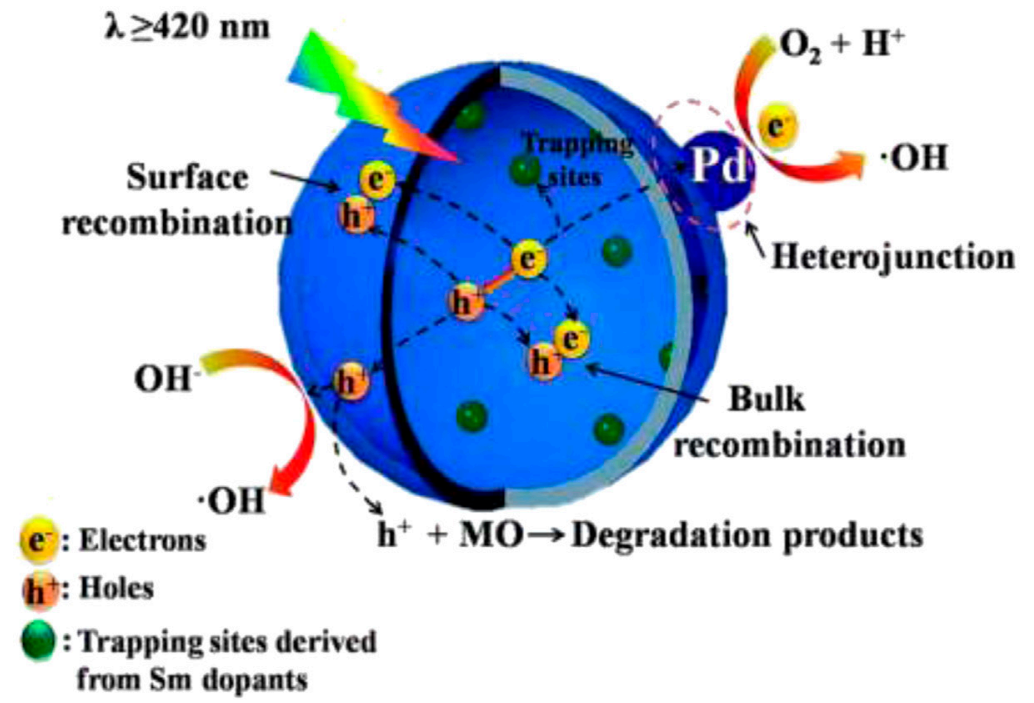

B

Heterojunction

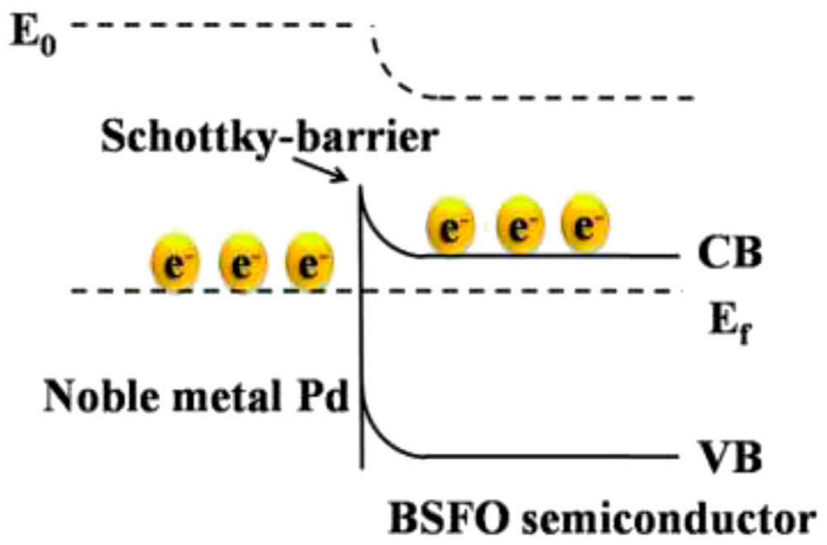

FIGURE 9 | (A) Schematic diagram for the proposed visible light photocatalytic mechanism of Pd/BSFO samples and (B) schematic illustration of Schottky barrier formed at the interface between Pd and BSFO (reproduced with permission (Wang S. et al., (2016).

subsequently $\mathrm{OH}$. The holes generated were transferred from the $\mathrm{VB}$ of $\mathrm{SmFeO}_{3}$ to $\mathrm{CuO}$ because the $\mathrm{VB}$ potential of $\mathrm{SmFeO}_{3}(+2.06)$ was not high enough to oxidize the adsorbed $-\mathrm{OH}(-\mathrm{OH} / \cdot \mathrm{OH}=+2.38 \mathrm{eV})$ and $\mathrm{H}_{2} \mathrm{O}\left(\mathrm{H}_{2} \mathrm{O} / \cdot \mathrm{OH}\right.$ $=+2.72 \mathrm{eV}$ ) to $\mathrm{OH}$; hence, holes in $\mathrm{SmFeO}_{3}$ could have directly oxidized the organics had it enough potentials. The formation of the heterojunction promoted the charge separation and suppressed the recombination of charge carriers.

The mechanism of reaction was summarized in Eqs. 1-4 (Behzadifard et al., 2018; Zhang and Jaroniec, 2018).

$$
\begin{aligned}
\mathrm{CuO} / \mathrm{SmFeO}_{3} & +\mathrm{hv} \text { (visible light }) \rightarrow \mathrm{e}^{-} \mathrm{CB}\left(\mathrm{CuO} \text { and } \mathrm{SmFeO}_{3}\right) \\
& +\mathrm{h}+\mathrm{VB}\left(\mathrm{CuO} \text { and } \mathrm{SmFeO}_{3}\right)
\end{aligned}
$$

$$
\begin{gathered}
2 \mathrm{e}^{-} \mathrm{CB}(\mathrm{CuO})+2 \mathrm{H}++\mathrm{O}_{2} \mathrm{H}_{2} \mathrm{O}_{2}, \\
\mathrm{H}_{2} \mathrm{O}_{2}+\mathrm{e}^{-} \rightarrow{ }^{-} \mathrm{OH}+\mathrm{OH},
\end{gathered}
$$

Pollutant $+\mathrm{OH} / \mathrm{h}^{+} \rightarrow$ Intermediates $\rightarrow$ degradation products.

\section{CONCLUSION AND RECOMMENDATION}

In this review, we discussed the recent progress in the field of photocatalysis and photoelectrocatalysis based on perovskite and perovskite-related materials. Recently, research has geared toward photocatalytic materials that are capable of absorbing light in the visible region. Perovskite and perovskite-related 
materials such as $\mathrm{BiFeO}_{3}, \mathrm{LaMnO}_{3}$, and $\mathrm{LaFeO}_{3}$, which are mostly visible-light active materials, are gaining attention as suitable anodic material for photoelectrocatalysis in degradation of organic pollutant due to their fascinating properties. Few photoelectrocatalysis degradation reports discussed here show that synergy of photocatalysis and electrolysis promotes better degradation performance. Reports have also shown that immobilizing catalyst onto substrate and application of bias potential aid in catalyst recovery, reduce electron-hole recombination, and increase charge resistance. In particular, the formation of perovskites as photoanodes through novel nanostructure engineering, surface modification with exotic element doping or cocatalyst loading, and innovative system design based on heterojunction configuration are excellent strategies for improving light harvest, charge separation, as well as surface reaction kinetics as compared to the single perovskites, for example, $\mathrm{BiFeO}_{3}$ doped with $\mathrm{Sm}$ and $\mathrm{Pd}$ (Wang S. et al., 2016). Agreeably, great progress has been made over the years; however, for ultimate realization of the inherent potential in perovskite, more work needs to be done in discovering new perovskites for photoelectrocatalysis. Furthermore, in order to maximize the degradation efficiencies in vast composition of organic pollutants, other advanced oxidation processes such as sono-photoelectrocatalysis and

\section{REFERENCES}

Abdi, M., Mahdikhah, V., and Sheibani, S. (2020). Visible light photocatalytic performance of $\mathrm{La}-\mathrm{Fe}$ co-doped $\mathrm{SrTiO} 3$ perovskite powder. Opt. Mater. 102, 109803. doi:10.1016/j.optmat.2020.109803

Acharya, S., Martha, S., Sahoo, P. C., and Parida, K. (2015). Glimpses of the modification of perovskite with graphene-analogous materials in photocatalytic applications. Inorg. Chem. Front. 2, 807-823. doi:10. 1039/c5qi00124b

Akinlolu, K., Omolara, B., Kehinde, O., and Shailendra, T. (2019). Synthesis and characterization of A site doped lanthanum based perovskite catalyst for the oxidation of soot. IOP Conf. Ser.: Mater. Sci. Eng. 509, 012062. doi:10.1088/ 1757-899X/509/1/012062

Alammar, T., Hamm, I., Wark, M., and Mudring, A.-V. (2015). Low-temperature route to metal titanate perovskite nanoparticles for photocatalytic applications. Appl. Catal. B: Environ. 178, 20-28. doi:10.1016/j.apcatb.2014.11.010

AlSalka, Y., Granone, L. I., Ramadan, W., Hakki, A., Dillert, R., and Bahnemann, D. W. (2019). Iron-based photocatalytic and photoelectrocatalytic nanostructures: facts, perspectives, and expectations. Appl. Catal. B: Environ. 244, 1065-1095. doi:10.1016/j.apcatb.2018.12.014

Arabi, A., Fazli, M., and Ehsani, M. H. (2018). Synthesis and characterization of calcium-doped lanthanum manganite nanowires as a photocatalyst for degradation of methylene blue solution under visible light irradiation. Bull. Mater. Sci. 41, 1-8. doi:10.1007/s12034-018-1590-6

Arandiyan, H., Wang, Y., Sun, H., Rezaei, M., and Dai, H. (2018). Ordered mesoand macroporous perovskite oxide catalysts for emerging applications. Chem. Commun. (Camb) 54, 6484-6502. doi:10.1039/c8cc01239c

Assirey, E. A. R. (2019). Perovskite synthesis, properties and their related biochemical and industrial application. Saudi Pharm. J. 27, 817-829. doi:10. 1016/j.jsps.2019.05.003

Baeissa, E. S. (2016). Photocatalytic degradation of malachite green dye using Au/ NaNbO3 nanoparticles. J. Alloys Compd. 672, 564-570. doi:10.1016/j.jallcom. 2016.02.024

Bahmani, M., Mowla, D., Esmaeilzadeh, F., and Ghaedi, M. (2020). BiFeO3-BiOI impregnation to $\mathrm{UiO}-66(\mathrm{Zr} / \mathrm{Ti})$ as a promising candidate visible-light-driven photocatalyst for boosting urea photodecomposition in a continuous flow-loop
photo-Fenton process can be incorporated with perovskite material for complete mineralization of the recalcitrant pollutants.

Therefore, for the advancement of perovskite-based material for photoelectrocatalysis treatment of water, continuous research into a better crystal structure for stability as well as performance improvement is essential. Perovskites with long-term stability and exceptional optical and electrochemical properties are essential for sustainability.

\section{AUTHOR CONTRIBUTIONS}

ON: conceptualization, writing-original draft. OA: conceptualization, writing-review and editing, supervision, funding acquisition, and resources.

\section{ACKNOWLEDGMENTS}

The authors wish to acknowledge the National Research Foundation of South Africa (CPRR Grant number 118546) and the Center for Nanomaterials Science Research, the University of Johannesburg for financial supports.

thin-film slurry flat-plate photoreactor. J. Solid State. Chem. 286, 121304. doi:10.1016/j.jssc.2020.121304

Behzadifard, Z., Shariatinia, Z., and Jourshabani, M. (2018). Novel visible light driven $\mathrm{CuO} / \mathrm{SmFeO} 3$ nanocomposite photocatalysts with enhanced photocatalytic activities for degradation of organic pollutants. J. Mol. Liquids 262, 533-548. doi:10.1016/j.molliq.2018.04.126

Bessegato, G. G., Guaraldo, T. T., de Brito, J. F., Brugnera, M. F., and Zanoni, M. V. B. (2015). Achievements and trends in photoelectrocatalysis: from environmental to energy applications. Electrocatalysis 6, 415-441. doi:10. 1007/s12678-015-0259-9

Biasotto, G., Simões, A. Z., Foschini, C. R., Zaghete, M. A., Varela, J. A., and Longo, E. (2011). Microwave-hydrothermal synthesis of perovskite bismuth ferrite nanoparticles. Mater. Res. Bull. 46, 2543-2547. doi:10.1016/j.materresbull.2011. 08.010

Bin Adnan, M. A., Arifin, K., Minggu, L. J., and Kassim, M. B. (2018). Titanatebased perovskites for photochemical and photoelectrochemical water splitting applications: a review. Int. J. Hydrogen Energ. 43, 23209-23220. doi:10.1016/j. ijhydene.2018.10.173

Brillas, E., and Martínez-Huitle, C. A. (2015). Decontamination of wastewaters containing synthetic organic dyes by electrochemical methods. An updated review. Appl. Catal. B: Environ. 166-167, 603-643. doi:10.1016/j.apcatb.2014. 11.016

Celorrio, V., Bradley, K., Weber, O. J., Hall, S. R., and Fermín, D. J. (2014). Photoelectrochemical properties of $\mathrm{LaFeO} 3$ Nanoparticles. ChemElectroChem 1 , 1667-1671. doi:10.1002/celc.201402192

Chen, C.Zhou, J., Geng, J., Bao, R., Wang, Z., Xia, J., et al. (2020). Perovskite LaNiO3/TiO2 step-scheme heterojunction with enhanced photocatalytic activity. Appl. Surf. Sci. 503, 144287. doi:10.1016/j.apsusc.2019.144287

Chen, X.He, X., Yang, X., Wu, Z., and Li, Y. (2020). Construction of novel 2D/1D g-C3N4/CaTiO3 heterojunction with face-to-face contact for boosting photodegradation of triphenylmethane dyes under simulated sunlight. J. Taiwan Inst. Chem. Eng. 107, 98-109. doi:10.1016/j.jtice.2019.12.002

Chen, Y.-W., Kuo, J.-L., and Chew, K.-H. (2017). Polar ordering and structural distortion in electronic domain-wall properties of BiFeO3. J. Appl. Phys. 122, 075103. doi:10.1063/1.4998456

Chu, Y., Tan, X., Shen, Z., Liu, P., Han, N., Kang, J., et al. (2018). Efficient removal of organic and bacterial pollutants by $\mathrm{Ag}-\mathrm{La} 0.8 \mathrm{Ca} 0.2 \mathrm{Fe} 0.94 \mathrm{O} 3-\delta$ perovskite via 
catalytic peroxymonosulfate activation. J. Hazard. Mater. 356, 53-60. doi:10. 1016/j.jhazmat.2018.05.044

Clark, S. J., and Robertson, J. (2007). Band gap and Schottky barrier heights of multiferroic BiFeO3. Appl. Phys. Lett. 90, 132903. doi:10.1063/1.2716868

Daghrir, R., Drogui, P., and Robert, D. (2012). Photoelectrocatalytic technologies for environmental applications. J. Photochem. Photobiol. A: Chem. 238, 41-52. doi:10.1016/j.jphotochem.2012.04.009

Demircivi, P., and Simsek, E. B. (2019). Visible-light-enhanced photoactivity of perovskite-type $\mathrm{W}$-doped $\mathrm{BaTiO} 3$ photocatalyst for photodegradation of tetracycline. J. Alloys Compd. 774, 795-802. doi:10.1016/j.jallcom.2018.09.354

Dhanasekaran, P., and Gupta, N. M. (2012). Factors affecting the production of $\mathrm{H} 2$ by water splitting over a novel visible-light-driven photocatalyst GaFeO3. Int. J. Hydrogen Energ. 37, 4897-4907. doi:10.1016/j.ijhydene. 2011.12 .068

Dixit, T. K., Sharma, S., and Sinha, A. S. K. (2020). Development of heterojunction in N-rGO supported bismuth ferrite photocatalyst for degradation of Rhodamine B. Inorg. Chem. Commun. 117, 107945. doi:10.1016/j.inoche. 2020.107945

Djoudi, L., and Omari, M. (2015). Synthesis and characterization of perovskite oxides LaAl1-x Ni x O3- $\delta(0 \leq \mathrm{x} \leq 0.6)$ via Co-precipitation method. J. Inorg. Organomet. Polym. 25, 796-803. doi:10.1007/s10904-014-0162-5

Dong, W., Liu, H., Bao, Q., and Gu, X. (2020). Facile synthesis of metastable CaTi2O5 nanostructure and its photocatalytic properties. Opt. Mater. 105, 109921. doi:10.1016/j.optmat.2020.109921

Etgar, L. (2016). Hole Conductor Free Perovskite-based Solar Cells, Switzerland: Springer

Fan, W., Sun, Z., Bai, Y., Wu, K., Zhou, J., and Cheng, Y. (2020). In situ growth of nanoparticles in A-site deficient ferrite perovskite as an advanced electrode for symmetrical solid oxide fuel cells. J. Power Sourc. 456, 228000. doi:10.1016/j. jpowsour.2020.228000

Fang, C., Geng, B., Liu, J., and Zhan, F. (2009). D-fructose molecule template route to ultra-thin $\mathrm{ZnSnO} 3$ nanowire architectures and their application as efficient photocatalyst. Chem. Commun. (Camb), 2350-2352. doi:10.1039/ b821459j

Fuentes, M. K., Kumar, A., Das, T., Kumar, V., Singh, S., Rai, V. S., et al. (2020). $\mathrm{BiFeO} 3$ perovskite as an efficient photocatalyst synthesised by soft chemical route. Mater. Technol. 105, 1-9. doi:10.1080/10667857.2020.1782061

Gade, R., Ahemed, J., Yanapu, K. L., Abate, S. Y., Tao, Y.-T., and Pola, S. (2018). Photodegradation of organic dyes and industrial wastewater in the presence of layer-type perovskite materials under visible light irradiation. J. Environ. Chem. Eng. 6, 4504-4513. doi:10.1016/j.jece.2018.06.057

Gao, T., Chen, Z., Niu, F., Zhou, D., Huang, Q., Zhu, Y., et al. (2015). Shapecontrolled preparation of bismuth ferrite by hydrothermal method and their visible-light degradation properties. J. Alloys Compd. 648, 564-570. doi:10. 1016/j.jallcom.2015.07.059

Garcia-Segura, S., and Brillas, E. (2017). Applied photoelectrocatalysis on the degradation of organic pollutants in wastewaters. J. Photochem. Photobiol. C: Photochem. Rev. 31, 1-35. doi:10.1016/j.jphotochemrev.2017.01.005

Ge, M. Z., Cao, C. Y., Huang, J. Y., Li, S. H., Zhang, S. N., Deng, S., et al. (2016). Synthesis, modification, and photo/photoelectrocatalytic degradation applications of $\mathrm{TiO} 2$ nanotube arrays: a review. Nanotechnology Rev. 5 (1), 75-112. doi:10.1515/ntrev-2015-0049

Georgieva, J., Valova, E., Armyanov, S., Philippidis, N., Poulios, I., and Sotiropoulos, S. (2012). Bi-component semiconductor oxide photoanodes for the photoelectrocatalytic oxidation of organic solutes and vapours: a short review with emphasis to TiO2-WO3 photoanodes. J. Hazard. Mater. 211-212, 30-46. doi:10.1016/j.jhazmat.2011.11.069

Gross-Sorokin, M. Y., Roast, S. D., and Brighty, G. C. (2006). Assessment of feminization of male fish in English rivers by the environment agency of England and Wales. Environ. Health Perspect. 114 Suppl 1, 147-151. doi:10. 1289/ehp. 8068

Guan, S., Li, R., Sun, X., Xian, T., and Yang, H. (2020). Construction of novel ternary $\mathrm{Au} / \mathrm{LaFeO} 3 / \mathrm{Cu} 2 \mathrm{O}$ composite photocatalysts for $\mathrm{RhB}$ degradation via photo-Fenton catalysis. Mater. Technol. 00, 1-13. doi:10.1080/10667857.2020. 1782062

Han, M., Ma, Z., Zhang, W., and Wang, H. (2020). The influences of hexadecyl trimethyl ammonium bromide on lanthanum titanate photocatalyst for ofloxacin degradation. J. Sol-gel Sci. Technol. 96, 480. doi:10.1007/s10971020-05341-9

Haron, W., Wisitsoraat, A., and Wongnawa, S. (2017). Nanostructured perovskite oxides - LaMO3 ( $\mathrm{M}=\mathrm{Al}, \mathrm{Co}, \mathrm{Fe})$ prepared by co-precipitation method and their ethanol-sensing characteristics. Ceramics Int. 43, 5032-5040. doi:10.1016/j. ceramint.2017.01.013

Haruna, A., Abdulkadir, I., and Idris, S. O. (2020). Synthesis, characterization and photocatalytic properties of $\mathrm{Bi} 0.85-\mathrm{XMXBa} 0.15 \mathrm{FeO} 3(\mathrm{M}=\mathrm{Na}$ and $\mathrm{K}, \mathrm{X}=0$, 0.1) perovskite-like nanoparticles using the sol-gel method. J. King Saud Univ. Sci. 32, 896-903. doi:10.1016/j.jksus.2019.05.005

Hbaieb, K., Rashid, K. K. A., and Kooli, F. (2017). Hydrogen production by autothermal reforming of dodecane over strontium titanate based perovskite catalysts. Int. J. Hydrogen Energ. 42, 5114-5124. doi:10.1016/j.ijhydene.2016. 11.127

Honorio, L. M. C., Oliveira, A. L. M. d., Silva Filho, E. C. d., Osajima, J. A., Hakki, A., Macphee, D. E., et al. (2020). Supporting the photocatalysts on ZrO2: an effective way to enhance the photocatalytic activity of SrSnO3. Appl. Surf. Sci. 528, 146991. doi:10.1016/j.apsusc.2020.146991

Huang, J.-R.Tan, X., Yu, T., Zhao, L., and Hu, W.-L. (2014). Enhanced photoelectrocatalytic and photoelectrochemical properties by high-reactive TiO 2/SrTiO 3 hetero-structured nanotubes with dominant $\{001\}$ facet of anatase TiO 2. Electrochimica Acta 146, 278-287. doi:10.1016/j.electacta.2014. 09.043

Huang, S.-T.Lee, W. W., Chang, J.-L., Huang, W.-S., Chou, S.-Y., and Chen, C.-C. (2014). Hydrothermal synthesis of $\mathrm{SrTiO}_{3}$ nanocubes: characterization, photocatalytic activities, and degradation pathway. J. Taiwan Inst. Chem. Eng. 45, 1927-1936. doi:10.1016/j.jtice.2014.02.003

Huerta-Flores, A. M., Torres-Martínez, L. M., Moctezuma, E., and Carrera-Crespo, J. E. (2018). Novel SrZrO3-Sb2O3 heterostructure with enhanced photocatalytic activity: band engineering and charge transference mechanism. J. Photochem. Photobiol. A: Chem. 356, 166-176. doi:10.1016/j. jphotochem.2017.12.049

Jayapandi, S., Lakshmi, D., Premkumar, S., Packiyaraj, P., and Anitha, K. (2018). Augmented photocatalytic and electrochemical activities of $\mathrm{Ag}$ tailored LaCoO3 perovskite semiconductor. Mater. Lett. 218, 205-208. doi:10.1016/j. matlet.2018.02.015

Jiang, E., Yang, L., Song, N., Zhang, X., Liu, C., and Dong, H. (2020). Multi-shelled hollow cube $\mathrm{CaTiO} 3$ decorated with $\mathrm{Bi} 12 \mathrm{O} 17 \mathrm{Cl} 2$ towards enhancing photocatalytic performance under the visible light. J. Colloid Interf. Sci. 576, 21-33. doi:10.1016/j.jcis.2020.05.019

Jiang, J., Jia, Y., Wang, Y., Chong, R., Xu, L., and Liu, X. (2019). Insight into efficient photocatalytic elimination of tetracycline over $\mathrm{SrTiO} 3(\mathrm{La}, \mathrm{Cr})$ under visiblelight irradiation: the relationship of doping and performance. Appl. Surf. Sci. 486, 93-101. doi:10.1016/j.apsusc.2019.04.261

Junploy, P., Thongtem, S., and Thongtem, T. (2013). Photoabsorption and photocatalysis of $\mathrm{SrSnO} 3$ produced by a cyclic microwave radiation. Superlattices and Microstructures 57, 1-10. doi:10.1016/j.spmi.2013.01.008

Kato, H., and Kudo, A. (1998). New tantalate photocatalysts for water decomposition into H2 and O2. Chem. Phys. Lett. 295, 487-492. doi:10. 1016/S0009-2614(98)01001-X

Kato, H., and Kudo, A. (2001). Water splitting into $\mathrm{H} 2$ and $\mathrm{O} 2$ on alkali tantalate photocatalysts $\mathrm{ATaO} 3(\mathrm{~A}=\mathrm{Li}, \mathrm{Na}$, and K). J. Phys. Chem. B 105, 4285-4292. doi:10.1021/jp004386b

Katz, E. A. (2020). Perovskite: name puzzle and German-Russian odyssey of discovery. Helvetica Chim. Acta 103, e200006. doi:10.1002/hlca.2020000610. 1002/hlca.202000061

Khalesi, A., Arandiyan, H. R., and Parvari, M. (2008b). Effects of lanthanum substitution by strontium and calcium in La-Ni-Al perovskite oxides in Dry reforming of methane. Chin. J. Catal. 29, 960-968. doi:10.1016/S1872-2067(08) 60079-0

Khalesi, A., Arandiyan, H. R., and Parvari, M. (2008a). Production of syngas by CO2Reforming on MxLa1-xNi0.3Al0.7O3-d(M = Li, Na, K) catalysts. Ind. Eng. Chem. Res. 47, 5892-5898. doi:10.1021/ie800111e

Kiani, A., Nabiyouni, G., Masoumi, S., and Ghanbari, D. (2019). A novel magnetic $\mathrm{MgFe} 2 \mathrm{O} 4-\mathrm{MgTiO} 3$ perovskite nanocomposite: rapid photo-degradation of toxic dyes under visible irradiation. Composites B: Eng. 175, 107080. doi:10. 1016/.j.compositesb.2019.107080 
Kong, J., Yang, T., Rui, Z., and Ji, H. (2019). Perovskite-based photocatalysts for organic contaminants removal: current status and future perspectives. Catal. Today 327, 47-63. doi:10.1016/j.cattod.2018.06.045

Kostyukhin, E. M., Kustov, A. L., and Kustov, L. M. (2019). One-step hydrothermal microwave-assisted synthesis of $\mathrm{LaFeO} 3$ nanoparticles. Ceramics Int. 45, 14384-14388. doi:10.1016/j.ceramint.2019.04.155

Kubacka, A., Fernández-García, M., and Colón, G. (2012). Advanced nanoarchitectures for solar photocatalytic applications. Chem. Rev. 112, 1555-1614. doi:10.1021/cr100454n

Kudo, A., Kato, H., and Nakagawa, S. (2000). Water splitting into H2and O2on new $\mathrm{Sr} 2 \mathrm{M} 2 \mathrm{O} 7(\mathrm{M}=\mathrm{Nb}$ and $\mathrm{Ta})$ photocatalysts with layered perovskite structures: factors affecting the photocatalytic activity. J. Phys. Chem. B 104, 571-575. doi:10.1021/jp9919056

Kumar, A.Kumar, A., and Krishnan, V. (2020). Perovskite oxide based materials for energy and environment-oriented photocatalysis. ACS Catal. 10 (17), 10253-10315. doi:10.1021/acscatal.0c02947

Kumar, A., Kumar, S., and Krishnan, V. (2019). "Synthesis and characterization of A site doped lanthanum based perovskite catalyst for the oxidation of soot," in Nanophotocatalysis and environmental applications. Cham: Springer, 139-165.

Kumar, P.Chand, P., and Singh, V. (2020). La3+ substituted BiFeO3-a proficient nano ferrite photo-catalyst under the application of visible light. Chem. Phys. Lett. 754, 137715. doi:10.1016/j.cplett.2020.137715

Kusmierek, E., and Chrzescijanska, E. (2015). Application of TiO2-RuO2/Ti electrodes modified with WO3 in electro- and photoelectrochemical oxidation of Acid Orange 7 dye. J. Photochem. Photobiol. A: Chem. 302, 59-68. doi:10.1016/j.jphotochem.2015.01.009

Labhasetwar, N., Saravanan, G., Kumar Megarajan, S., Manwar, N., Khobragade, R., Doggali, P., et al. (2015). Perovskite-type catalytic materials for environmental applications. Sci. Technol. Adv. Mater. 16, 036002. doi:10. 1088/1468-6996/16/3/036002

Lakhera, S. K., Hafeez, H. Y., Veluswamy, P., Ganesh, V., Khan, A., Ikeda, H., et al. (2018). Enhanced photocatalytic degradation and hydrogen production activity of in situ grown $\mathrm{TiO} 2$ coupled NiTiO3 nanocomposites. Appl. Surf. Sci. 449, 790-798. doi:10.1016/j.apsusc.2018.02.136

Yang, Y., Chen, Q., Yin, Z., and Li, J. (2009). Study on the photocatalytic activity of K2La2Ti3O10 doped with vanadium (V). J. Alloys Compd. 488, 364-369. doi:10. 1016/j.jallcom.2009.08.136

Li, X., and Zang, J. (2011). Hydrothermal synthesis and characterization of Lanthanum-doped $\mathrm{NaTaO} 3$ with high photocatalytic activity. Catal. Commun. 12, 1380-1383. doi:10.1016/j.catcom.2011.05.004

Liu, D. R., Jiang, Y. S., and Gao, G. M. (2011). Photocatalytic degradation of an azo dye using $\mathrm{N}$-doped $\mathrm{NaTaO} 3$ synthesized by one-step hydrothermal process. Chemosphere 83, 1546-1552. doi:10.1016/j.chemosphere.2011.01.033

Liu, J., He, F., Chen, L., Qin, X., Zhao, N., Huang, Y., et al. (2016). Novel hexagonal$\mathrm{YFeO} 3 / \mathrm{a}-\mathrm{Fe} 2 \mathrm{O} 3$ heterojunction composite nanowires with enhanced visible light photocatalytic activity. Mater. Lett. 165, 263-266. doi:10.1016/j.matlet. 2015.12.008

Lu, L., Lv, M., Wang, D., Liu, G., and Xu, X. (2017). Efficient photocatalytic hydrogen production over solid solutions Sr1-xBixTil-xFexO3 $(0 \leq \mathrm{x} \leq 0.5)$. Appl. Catal. B: Environ. 200, 412-419. doi:10.1016/j.apcatb.2016.07.035

Malathi, A., Arunachalam, P., Kirankumar, V. S., Madhavan, J., and Al-Mayouf, A. M. (2018). An efficient visible light driven bismuth ferrite incorporated bismuth oxyiodide (BiFeO3/BiOI) composite photocatalytic material for degradation of pollutants. Opt. Mater. 84, 227-235. doi:10.1016/j.optmat.2018.06.067

Malpass, G. R., Miwa, D. W., Machado, S. A., and Motheo, A. J. (2010). SnO(2)based materials for pesticide degradation. J. Hazard. Mater. 180, 145-151. doi:10.1016/j.jhazmat.2010.04.006

Meng, W., Hu, R., Yang, J., Du, Y., Li, J., and Wang, H. (2016). Influence of lanthanum-doping on photocatalytic properties of $\mathrm{BiFeO} 3$ for phenol degradation. Chin. J. Catal. 37, 1283-1292. doi:10.1016/S1872-2067(16)62449-X

Meng, X., Zhang, Z., and Li, X. (2015). Synergetic photoelectrocatalytic reactors for environmental remediation: a review. J. Photochem. Photobiol. C: Photochem. Rev. 24, 83-101. doi:10.1016/j.jphotochemrev.2015.07.003

Modak, B., and Ghosh, S. K. (2014). Improvement of photocatalytic activity of $\mathrm{NaTaO} 3$ under visible light by $\mathrm{N}$ and $\mathrm{F}$ doping. Chem. Phys. Lett. 613, 54-58. doi:10.1016/j.cplett.2014.08.054
Mužina, K., Tkalčević, M., Brleković, F., Munda, I. K., Šipušić, J., and Kurajica, S. (2020). Sol-gel synthesis and characterization of lithium and cerium codoped perovskite. 9, 17-24. doi:10.32732/jma.2020.9.1.17

Mukherjee, A., Chakrabarty, S., Kumari, N., Su, W. N., and Basu, S. (2018). Visiblelight-mediated electrocatalytic activity in reduced graphene oxide-supported bismuth ferrite. Acs Omega 3 (6), 5946-5957. doi:10.1021/acsomega.8b00708

Muñoz-Gil, D., Urones-Garrote, E., Pérez-Coll, D., Amador, U., and GarcíaMartín, S. (2018). Crystal structure and compositional effects on the electrical and electrochemical properties of $\mathrm{GdBaCo} 2-\mathrm{xMnxO}+\delta(0 \leq \mathrm{x} \leq$ 2) oxides for use as air electrodes in solid oxide fuel cells. J. Mater. Chem. A. 6 , 5452-5460. doi:10.1039/c7ta10923g

Nakhostin Panahi, P., Rasoulifard, M. H., and Babaei, S. (2020). Photocatalytic activity of cation (Mn) and anion (N) substitution in $\mathrm{LaCoO} 3$ nanoperovskite under visible light. Rare Met. 39, 139-146. doi:10.1007/ s12598-019-01329-9

Neaton, J. B., Ederer, C., Waghmare, U. V., Spaldin, N. A., and Rabe, K. M. (2005). First-principles study of spontaneous polarization in multiferroicBiFeO3. Phys. Rev. B 71, 1-9. doi:10.1103/PhysRevB.71.014113

Ni, M., Leung, M. K. H., Leung, D. Y. C., and Sumathy, K. (2007). A review and recent developments in photocatalytic water-splitting using $\mathrm{TiO} 2$ for hydrogen production. Renew. Sustain. Energ. Rev. 11, 401-425. doi:10.1016/j.rser.2005. 01.009

Oliva, J., Garcia, C. R., Verduzco, E., Martinez, A. I., Manthiram, A., and Padmasree, K. P. (2017). Enhancing the photocatalytic activity of the perovskite-based intergrowth oxide Sr3.2La0.8Fe1.5Co1.5O10- $\delta$ with Ca substitution. Ceramics Int. 43, 14074-14081. doi:10.1016/j.ceramint.2017.07.143

Orimolade, B. O., and Arotiba, O. A. (2020). Towards visible light driven photoelectrocatalysis for water treatment: application of a FTO/BiVO4/Ag2S heterojunction anode for the removal of emerging pharmaceutical pollutants. Sci. Rep. 10, 1-13. doi:10.1038/s41598-020-62425-w

Orimolade, B. O., Koiki, B. A., Peleyeju, G. M., and Arotiba, O. A. (2019). Visible light driven photoelectrocatalysis on a FTO/BiVO4/BiOI anode for water treatment involving emerging pharmaceutical pollutants. Electrochimica Acta 307, 285-292. doi:10.1016/j.electacta.2019.03.217

Orimolade, B. O., Zwane, B. N., Koiki, B. A., Tshwenya, L., Peleyeju, G. M., Mabuba, N., et al. (2020). Solar photoelectrocatalytic degradation of ciprofloxacin at a $\mathrm{FTO} / \mathrm{BiVO} / \mathrm{MnO} 2$ anode: kinetics, intermediate products and degradation pathway studies. J. Environ. Chem. Eng. 8, 103607. doi:10. 1016/j.jece.2019.103607

Park, N. G., Grätzel, M., and Miyasaka, T. (2016). Organic-inorganic halide perovskite photovoltaics: from fundamentals to device architectures. Springer International Publishing. doi:10.1007/978-3-319-35114-8

Peleyeju, M. G., and Arotiba, O. A. (2018). Recent trend in visible-light photoelectrocatalytic systems for degradation of organic contaminants in water/wastewater. Environ. Sci. Water Res. Technol. 4, 1389-1411. doi:10. 1039/c8ew00276b

Phoon, B. L., Lai, C. W., Pan, G.-T., Yang, T. C.-K., and Juan, J. C. (2018). One-pot hydrothermal synthesis of strontium titanate nanoparticles photoelectrode using electrophoretic deposition for enhancing photoelectrochemical water splitting. Ceramics Int. 44, 9923-9933. doi:10.1016/j.ceramint.2018.03.017

Pisarev, R. V., Moskvin, A. S., Kalashnikova, A. M., and Rasing, T. (2009). Charge transfer transitions in multiferroicBiFeO3and related ferrite insulators. Phys. Rev. B 79. doi:10.1103/PhysRevB.79.235128

Priyatharshni, S., Rajesh Kumar, S., Viswanathan, C., and Ponpandian, N. (2020). Morphologically tuned $\mathrm{LaMnO} 3$ as an efficient nanocatalyst for the removal of organic dye from aqueous solution under sunlight. J. Environ. Chem. Eng. 8, 104146. doi:10.1016/j.jece.2020.104146

Qian, X., Chen, Z., Yang, X., Zhao, W., Liu, C., Sun, T., et al. (2020). Perovskite cesium lead bromide quantum dots: a new efficient photocatalyst for degrading antibiotic residues in organic system. J. Clean. Prod. 249, 119335. doi:10.1016/j. jclepro.2019.119335

Qu, L., Lang, J., Wang, S., Chai, Z., Su, Y., and Wang, X. (2016). Nanospherical composite of WO3 wrapped $\mathrm{NaTaO} 3$ : improved photodegradation of tetracycline under visible light irradiation. Appl. Surf. Sci. 388, 412-419. doi:10.1016/j.apsusc.2015.12.095

Ramadan, W., Shaikh, P. A., Ebrahim, S., Ramadan, A., Hannoyer, B., Jouen, S., et al. (2013). Highly efficient photocatalysis by $\mathrm{BiFeO} 3 / \alpha(\gamma)-\mathrm{Fe} 2 \mathrm{O} 3$ 
ferromagnetic nano $\mathrm{p} / \mathrm{n}$ junctions formed by dopant-induced phase separation. J. Nanopart Res. 15 (8), 1-10. doi:10.1007/s11051-013-1848-2

Rao, M. P., Nandhini, V. P., Wu, J. J., Syed, A., Ameen, F., and Anandan, S. (2018). Synthesis of $\mathrm{N}$-doped potassium tantalate perovskite material for environmental applications. J. Solid State. Chem. 258, 647-655. doi:10.1016/ j.jssc.2017.11.031

Rekavandi, N., Malekzadeh, A., and Ghiasi, E. (2019). Methyl orange degradation using nano-LaMnO 3 as a green catalyst under the mild conditions. Nanochem Res. 4, 1-10. doi:10.22036/ncr.2019.01.001

Remya, K. P., Prabhu, D., Joseyphus, R. J., Bose, A. C., Viswanathan, C., and Ponpandian, N. (2020). Tailoring the morphology and size of perovskite $\mathrm{BiFeO} 3$ nanostructures for enhanced magnetic and electrical properties. Mater. Des. 192, 108694. doi:10.1016/j.matdes.2020.108694

Ridzuan, N. D. M., Kaus, N. H. M., Lazim, M. A. S. M., Kobayashi, T., Adnan, R., Othman, M. Z., et al. (2020). Photocatalytic heterostructures-based BiFeO3 embedded liquid natural rubber (LNR) for highly removal of cationic dye under direct sunlight. J. Environ. Chem. Eng. 8 (5), 104152. doi:10.1016/j.jece.2020. 104152

Rosy, A., and Kalpana, G. (2018). Reduced graphene oxide/strontium titanate heterostructured nanocomposite as sunlight driven photocatalyst for degradation of organic dye pollutants. Curr. Appl. Phys. 18, 1026-1033. doi:10.1016/j.cap.2018.05.019

Sati, P. C., Kumar, M., Chhoker, S., and Jewariya, M. (2015). Influence of Eu substitution on structural, magnetic, optical and dielectric properties of $\mathrm{BiFeO} 3$ multiferroic ceramics. Ceramics Int. 41, 2389-2398. doi:10.1016/j.ceramint. 2014.10.053

Lim, P. F., Leong, K. H., Sim, L. C., Saravanan, P., and Abd Aziz, A. (2019). Perovskite Oxide-Based Photocatalysts for Excellent Visible Light-Driven Photocatalysis and Energy Conversion. in Plant Nanobionics, Cham: Springer, 35-54.

Shawky, A., Mohamed, R. M., Mkhalid, I. A., Youssef, M. A., and Awwad, N. S. (2020). Visible light-responsive $\mathrm{Ag} / \mathrm{LaTiO} 3$ nanowire photocatalysts for efficient elimination of atrazine herbicide in water. J. Mol. Liquids 299, 112163. doi:10.1016/j.molliq.2019.112163

Shirazi, P., Rahbar, M., Behpour, M., Ashrafi, M., and Behpour, M. (2020). La2MnTiO6 double perovskite nanostructures as highly efficient visible light photocatalysts. New J. Chem. 44, 231-238. doi:10.1039/c9nj04932k

Simsek, E. B., Tuna, Ö., and Balta, Z. (2019). Construction of stable perovskite-type $\mathrm{LaFeO} 3$ particles on polymeric resin with boosted photocatalytic Fenton-like decaffeination under solar irradiation. Sep. Purif. Technol. 237, 116384. doi:10. 1016/j.seppur.2019.116384

Sirés, I., Brillas, E., Oturan, M. A., Rodrigo, M. A., and Panizza, M. (2014). Electrochemical advanced oxidation processes: today and tomorrow. A review. Environ. Sci. Pollut. Res. 21, 8336-8367. doi:10.1007/s11356-014-2783-1

Sirés, I., and Brillas, E. (2012). Remediation of water pollution caused by pharmaceutical residues based on electrochemical separation and degradation technologies: a review. Environ. Int. 40, 212-229. doi:10.1016/j. envint.2011.07.012

Sosnowska, I., Loewenhaupt, M., David, W. I. F., and Ibberson, R. M. (1992). Investigation of the unusual magnetic spiral arrangement in $\mathrm{BiFeO} 3$. Physica B: Condensed Matter 180-181, 117-118. doi:10.1016/09214526(92)90678-L

Tang, P., Chen, H., Cao, F., and Pan, G. (2011). Magnetically recoverable and visible-light-driven nanocrystalline $\mathrm{YFeO} 3$ photocatalysts. Catal. Sci. Technol. 1, 1145-1148. doi:10.1039/c1cy00199j

Teresita, V. M., Manikandan, A., Josephine, B. A., Sujatha, S., and Antony, S. A. (2016). Electromagnetic properties and humidity-sensing studies of magnetically recoverable $\mathrm{LaMg} \times \mathrm{Fe} 1-\mathrm{x} \quad \mathrm{O} 3-\delta$ perovskites nanophotocatalysts by sol-gel route. J. Supercond. Nov. Magn. 29, 1691-1701. doi:10.1007/s10948-016-3465-7

Tomar, R., Prajapati, R., Verma, S., and Rana, N. (2021). Enhanced photoluminescence and efficient photocatalytic activity of Sn doped barium titanate. Mater. Today Proc. 34, 608-611. doi:10.1016/j.matpr.2020.01.543

Torregrosa-Rivero, V., Albaladejo-Fuentes, V., Sánchez-Adsuar, M.-S., and IllánGómez, M.-J. (2017). Copper doped $\mathrm{BaMnO} 3$ perovskite catalysts for $\mathrm{NO}$ oxidation and NO2-assisted diesel soot removal. RSC Adv. 7, 35228-35238. doi:10.1039/c7ra04980c
Umukoro, E. H., Peleyeju, M. G., Idris, A. O., Ngila, J. C., Mabuba, N., Rhyman, L., et al. (2018). Photoelectrocatalytic application of palladium decorated zinc oxide-expanded graphite electrode for the removal of 4-nitrophenol: experimental and computational studies. RSC Adv. 8, 10255-10266. doi:10. 1039/c8ra00180d

Umukoro, E. H., Peleyeju, M. G., Ngila, J. C., and Arotiba, O. A. (2016). Photocatalytic degradation of acid blue 74 in water using Ag-Ag 2 O-Zno nanostuctures anchored on graphene oxide. Solid State. Sci. 51, 66-73. doi:10. 1016/j.solidstatesciences.2015.11.015

Umukoro, E. H., Peleyeju, M. G., Ngila, J. C., and Arotiba, O. A. (2017). Towards wastewater treatment: photo-assisted electrochemical degradation of 2nitrophenol and orange II dye at a tungsten trioxide-exfoliated graphite composite electrode. Chem. Eng. J. 317, 290-301. doi:10.1016/j.cej.2017.02.084

Venkatesh, G., Geerthana, M., Prabhu, S., Ramesh, R., and Prabu, K. M. (2020a). Enhanced photocatalytic activity of reduced graphene oxide/SrSnO3 nanocomposite for aqueous organic pollutant degradation. Optik 206, 164055. doi:10.1016/j.ijleo.2019.164055

Venkatesh, G., Prabhu, S., Geerthana, M., Baskaran, P., Ramesh, R., and Prabu, K. M. (2020b). Facile synthesis of $\mathrm{rGO} / \mathrm{CaSnO} 3$ nanocomposite as an efficient photocatalyst for the degradation of organic dye. Optik 212, 164716. doi:10. 1016/j.ijleo.2020.164716

Verduzco, L. E., Garcia-Diaz, R., Oliva, J., Martinez, A. I., Gomez-Solis, C., Garcia, C. R., et al. (2018). Enhanced photocatalytic activity of layered perovskite oxides Sr2.7-xCaxLn0.3Fe2O7- $\delta$ for MB degradation. Ceramics Int. 44, 17079-17086. doi:10.1016/j.ceramint.2018.06.155

Wang, F., Chen, D., Zhang, N., Wang, S., Qin, L., Sun, X., et al. (2017). Oxygen vacancies induced by zirconium doping in bismuth ferrite nanoparticles for enhanced photocatalytic performance. J. Colloid Interf. Sci. 508, 237-247. doi:10.1016/j.jcis.2017.08.056

Wang, L., Xia, L., Wu, Y., and Tian, Y. (2016). Zr-doped $\beta$-in2S3 ultrathin nanoflakes as photoanodes: enhanced visible-light-driven photoelectrochemical water splitting. ACS Sustain. Chem. Eng. 4, 2606-2614. doi:10.1021/acssuschemeng.6b00090

Wang, Q., Zhou, S., Xiao, S., Wei, F., Zhao, X., Qu, J. e., et al. (2018). Novel perovskite-based composites, $\mathrm{La}_{1-\mathrm{x}} \mathrm{NdxFeO}_{3} @$ activated carbon, as efficient catalysts for the degradation of organic pollutants by heterogeneous electro-Fenton reactions. RSC $A d v$. 8, 14775-14786. doi:10.1039/ c8 8 ra00244d

Wang, S., Chen, D., Niu, F., Zhang, N., Qin, L., and Huang, Y. (2016). Pd cocatalyst on Sm-doped $\mathrm{BiFeO} 3$ nanoparticles: synergetic effect of a Pd cocatalyst and samarium doping on photocatalysis. RSC Adv. 6, 34574-34587. doi:10.1039/ c6ra01140c

Wang, W., Bi, J., Wu, L., Li, Z., and Fu, X. (2009). Hydrothermal synthesis and catalytic performances of a new photocatalyst $\mathrm{CaSnO} 3$ with microcube morphology. Scripta Materialia 60, 186-189. doi:10.1016/j.scriptamat.2008. 10.001

Wang, W., Liang, S., Ding, K., Bi, J., Yu, J. C., Wong, P. K., et al. (2014). Microwave hydrothermal synthesis of $\mathrm{MSnO} 3(\mathrm{M} 2+=\mathrm{Ca} 2+, \mathrm{Sr} 2+, \mathrm{Ba} 2+$ ): effect of $\mathrm{M} 2+$ on crystal structure and photocatalytic properties. J. Mater. Sci. 49, 1893-1902. doi:10.1007/s10853-013-7880-x

Wu, J.-g., Fang, T., Cai, R., Li, S.-y., Wang, Y., Zhao, C.-e., et al. (2016). Fabrication of an $\mathrm{Ag} / \mathrm{Fe} 2 \mathrm{O} 3 / \mathrm{ZnO}$ ternary composite with enhanced photocatalytic performance. RSC Adv. 6, 4145-4150. doi:10.1039/c5ra20403h

Wu, X.-J., Niu, C.-G., Zhang, L., Liang, C., and Zeng, G.-M. (2017). An in depth mechanism insight of the degradation of multiple refractory pollutants via a novel SrTiO3/BiOI heterojunction photocatalysts. J. Catal. 356, 283-299. doi:10.1016/j.jcat.2017.10.022

Wei, H., Luo, C., Huangfu, G., and Guo, Y. (2020). Boosting the photocatalytic ability of bandgap engineered $(\mathrm{Na} 0.5 \mathrm{Bi} 0.5) \mathrm{TiO} 3-\mathrm{BaTiO} 3$ by $\mathrm{N}-\mathrm{Ni}$ codoping. J. Phys. Chem. C 124, 11810-11818. doi:10.1021/acs.jpcc. 0c02542

Yahya, N., Nasir, A. M., Daub, N. A., Aziz, F., Aizat, A., Jaafar, J., et al. (2020). Visible light-driven perovskite-based photocatalyst for wastewater treatment. In Handbook of Smart Photocatalytic Materials, Amsterdam, Netherlands: . Elsevier, 265-302.

Yahya, N., Aziz, F., Enriquez, M. A. O. A., Aizat, A., Lau, W. J., Yusof, N., et al. (2018). Preparation and characterization of Lafeo3 using dual-complexing 
agents for photodegradation of humic acid. Environ. Eco. Sci. (EES) 2 (2), 30-34. doi:10.26480/ees.02.2018.30.34

Yahya, N., Aziz, F., Jamaludin, A., Aizat, A., Mutalib, M. A., Jaafar, J., et al. (2019). Effects of the citric acid addition on the morphology, surface area, and photocatalytic activity of $\mathrm{LaFeO} 3$ nanoparticles prepared by glucose-based gel combustion methods. Ind. Eng. Chem. Res. 58, 609-617. doi:10.1021/acs.iecr.8b04263

Yao, W. F., Xu, X. H., Wang, H., Zhou, J. T., Yang, X. N., Zhang, Y., et al. (2004). Photocatalytic property of perovskite bismuth titanate. Appl. Catal. B. Environ. 52, 109-116. doi:10.1016/j.apcatb.2004.04.002

Yao, L., Chen, Z., Li, J., and Shi, C. (2020). Creation of oxygen vacancies to activate lanthanum-doped bismuth titanate nanosheets for efficient synchronous photocatalytic removal of $\mathrm{Cr}(\mathrm{VI})$ and methyl orange. J. Mol. Liquids 314, 113613. doi:10.1016/j.molliq.2020.113613

Yu, X., Wang, J., Fu, X., Meng, H., Zhu, Y., and Zhang, Y. (2020). Construction of $\mathrm{Z}$-scheme SrTiO3/Ag/Ag3PO4 photocatalyst with oxygen vacancies for highly efficient degradation activity towards tetracycline. Separat. Purif. Technol. 241, 116718. doi:10.1016/j.seppur.2020.116718

Zhang, D., Lv, S., and Luo, Z. (2020). A study on the photocatalytic degradation performance of a $[\mathrm{KNbO} 3] 0.9-[\mathrm{BaNi} 0.5 \mathrm{Nb} 0.5 \mathrm{O} 3-\delta] 0.1$ perovskite. $R S C A d v$. 10, 1275-1280. doi:10.1039/c9ra07310h

Zhang, H., Chen, G., Li, Y., and Teng, Y. (2010). Electronic structure and photocatalytic properties of copper-doped CaTiO3. Int. J. Hydrogen Energ. 35, 2713-2716. doi:10.1016/j.ijhydene.2009.04.050

Zhang, H., Shimizu, Y., Teraoka, Y., Miura, N., and Yamazoe, N. (1990). Oxygen sorption and catalytic properties of La1\$minus; $\mathrm{XSrxCo1} \$$ minus;yFeyO3 Perovskitetype oxides. J. Catal. 121, 432-440. doi:10.1016/0021-9517(90)90251-E

Zhang, L., and Jaroniec, M. (2018). Toward designing semiconductorsemiconductor heterojunctions for photocatalytic applications. Appl. Surf. Sci. 430, 2-17. doi:10.1016/j.apsusc.2017.07.192

Zhang, Q., Huang, Y., Peng, S., Zhang, Y., Shen, Z., Cao, J.-j., et al. (2017). Perovskite LaFeO3-SrTiO3 composite for synergistically enhanced NO removal under visible light excitation. Appl. Catal. B: Environ. 204, 346-357. doi:10. 1016/j.apcatb.2016.11.052
Zhang, W., Li, H., Ma, Z., Li, H., and Wang, H. (2019). Photocatalytic degradation of azophloxine on porous La2Ti2O7 prepared by sol-gel method. Solid State. Sci. 87, 58-63. doi:10.1016/j.solidstatesciences.2018.11.004

Zhang, W., Tang, J., and Ye, J. (2007). Structural, photocatalytic, and photophysical properties of perovskite $\mathrm{MSnO} 3(\mathrm{M}=\mathrm{Ca}, \mathrm{Sr}$, and $\mathrm{Ba})$ photocatalysts. J. Mater. Res. 22, 1859-1871. doi:10.1557/jmr.2007.0259

Zhang, W. F., Tang, J., and Ye, J. (2006). Photoluminescence and photocatalytic properties of SrSnO3 perovskite. Chem. Phys. Lett. 418, 174-178. doi:10.1016/j. cplett.2005.10.122

Zhang, Y., Jin, Z., Chen, L., and Wang, J. (2019). SrFexNi1-xO3- $\delta$ perovskites coated on $\mathrm{Ti}$ anodes and their electrocatalytic properties for cleaning nitrogenous wastewater. Materials 12, 511. doi:10.3390/ma12030511

Zhu, A., Zhao, Q., Li, X., and Shi, Y. (2014). BiFeO3/TiO2 nanotube arrays composite electrode: construction, characterization, and enhanced photoelectrochemical properties. ACS Appl. Mater. Inter. 6, 671-679. doi:10. 1021/am404774z

Zhu, H., Zhang, P., and Dai, S. (2015). Recent Advances of lanthanum-based perovskite oxides for catalysis. ACS Catal. 5, 6370-6385. doi:10.1021/acscatal.5b01667

Zhu, J., Li, H., Zhong, L., Xiao, P., Xu, X., Yang, X., et al. (2014). Perovskite oxides: preparation, characterizations, and applications in heterogeneous catalysis. ACS Catal. 4, 2917-2940. doi:10.1021/cs500606g

Conflict of Interest: The authors declare that the research was conducted in the absence of any commercial or financial relationships that could be construed as a potential conflict of interest.

Copyright (c) 2021 Nkwachukwu and Arotiba. This is an open-access article distributed under the terms of the Creative Commons Attribution License (CC $B Y)$. The use, distribution or reproduction in other forums is permitted, provided the original author(s) and the copyright owner(s) are credited and that the original publication in this journal is cited, in accordance with accepted academic practice. No use, distribution or reproduction is permitted which does not comply with these terms. 